\title{
WestVirginiaUniversity
}

THE RESEARCH REPOSITORY @ WVU

Graduate Theses, Dissertations, and Problem Reports

2009

\section{Text format, text comprehension, and related reader variables}

Jodi L. Nichols

West Virginia University

Follow this and additional works at: https://researchrepository.wvu.edu/etd

\section{Recommended Citation}

Nichols, Jodi L., "Text format, text comprehension, and related reader variables" (2009). Graduate Theses, Dissertations, and Problem Reports. 2930.

https://researchrepository.wvu.edu/etd/2930

This Dissertation is protected by copyright and/or related rights. It has been brought to you by the The Research Repository @ WVU with permission from the rights-holder(s). You are free to use this Dissertation in any way that is permitted by the copyright and related rights legislation that applies to your use. For other uses you must obtain permission from the rights-holder(s) directly, unless additional rights are indicated by a Creative Commons license in the record and/ or on the work itself. This Dissertation has been accepted for inclusion in WVU Graduate Theses, Dissertations, and Problem Reports collection by an authorized administrator of The Research Repository @ WVU.

For more information, please contact researchrepository@mail.wvu.edu. 
TEXT FORMAT, TEXT COMPREHENSION, AND RELATED READER VARIABLES

\author{
Jodi L. Nichols
}

\author{
Dissertation submitted to the \\ College of Human Resources and Education \\ at West Virginia University \\ in partial fulfillment of the requirements \\ for the degree of
}

\author{
Doctor of Education \\ in \\ Curriculum and Instruction
}

\author{
Steven Rinehart, Ed.D., Chair \\ Allison Swan-Dagen, Ph.D. \\ Perry Phillips, Ed.D. \\ Phillip Ice, Ed.D. \\ Charline Barnes Rowland, Ed.D. \\ Department of Curriculum and Instruction
}

\author{
Morgantown, West Virginia
}

2009

Keywords: text comprehension, electronic text, gender, prior knowledge

Copyright 2009 Jodi L. Nichols 


\section{ABSTRACT \\ Text Format, Text Comprehension, and Related Reader Variables}

Jodi L. Nichols

This investigation explored relationships between format of text (electronic or printbased) and reading comprehension of adolescent readers. Also in question were potential influences on comprehension from related measures including academic placement of participants, gender, prior knowledge of the content, and overall reading ability. Influences were measured through an unaided text retell and a constructed-response assessment with traditional questioning. Participants' reading preferences and self-reported reading behaviors were also explored.

Findings from regression analyses revealed that format of the text was not a significant predictor of reading comprehension for seventh grade students, despite participants' self-reported preference to reading electronic text. Conversely, participants' academic placements and overall reading abilities were significant predictors of comprehension, as measured by both retell and constructed-response assessments. Having prior knowledge of the subject content was advantageous for participants on retell measures but did not appear to impact performance on the constructed response assessment. Gender, however, significantly predicted comprehension on the constructed -response assessment but did not impact retell measures. There were no significant two-way interactions between the format of the text and academic placement, gender, prior knowledge, or overall reading ability.

Findings from a two-part written survey revealed that seventh grade students in this study prefer reading electronic text, as compared to conventionally printed text. Additionally, those who read electronic text reported utilizing a greater number of comprehension strategies than those reading conventionally printed text. Males, as well as students in lower academic placement levels, reported using strategies most often. 


\section{ACKNOWLEDGEMENTS}

The pursuit of this degree would not have been possible without the support and encouragement of my family, friends, colleagues, and committee members. Without all of you, this dream would not have come to fruition. I am extremely appreciative of the role that each of you has played, both personal and professional.

First and foremost, I would like to express my sincere appreciation to my family for your unwavering love and support. Mom and Dad, from the time I was a young child, you have been my source of inspiration and have instilled in me the value of hard work and diligence. Because of the two of you, I had the confidence to pursue this degree and tackle this research study. Sean, this accomplishment would not have been possible without you standing behind me, providing me the much needed emotional support, and encouraging me each step of the way. I will forever be grateful for the sacrifices that you made in an effort to help me achieve this goal. Thank you for the daily reminders about the possibilities that await me. To my two wonderful sons, Camden and Linden, I hope that my work on this project will serve as a model for you and inspire you to pursue your own dreams, while realizing that no mountain is too high and no challenge is too great. If I can do it, so can you.

Ann, you and I were brought together for a reason, and I am so very thankful for your friendship. I will forever be grateful for your continual words of wisdom and kindness. We have celebrated the highs together and supported each other through the challenges of a rigorous, demanding program. Together, we made it!

To my colleagues at “Western Middle School”, I appreciate each of you lending your areas of expertise to me in a variety of areas. Sincere thanks go to Jane Wildesen, Jason Shank, Adrienne Ingram, Annie Savage, Mark Ravenscroft, and Sara Ramsey. Sara, my hope is that 
someday I will have the ability to impact others as you have impacted me, as both my eighth grade English teacher and colleague. It is ironic that after twenty-five years, you would be reading my work again and offering the same type of praise and encouragement that you did when I was a child.

Finally, I have been truly blessed with an extraordinary committee. Dr. Rinehart, I cannot thank you enough for the wonderful opportunities that you extended to me during my four years at WVU. The time that you invested in me, and mentored me, are much appreciated. Allison, your impact upon me has been immeasurable. When I was filled with uncertainty, you made me believe in myself and my capabilities. You read my work with a critical eye, and this finished product is better because of you. Phil, your expertise, as well as your friendship, will always be appreciated. You made me a more confident student and researcher. Charline, thanks for your open door, allowing me to vent when I was feeling discouraged. Your time and commitment to my project are much appreciated, and I look forward to working with you in the future. Finally, Dr. Phillips, thank you for believing in the value of this research and agreeing to come on board for the journey. It has been a memorable ride, and I am so pleased to share this finished product with all of you. It is my hope that this research will ultimately impact the children who make me realize every single day that I have the best job in the world. I am, and will always be, a teacher. 


\section{TABLE OF CONTENTS}

Chapter 1 Introduction and Problem Statement.............................................................................

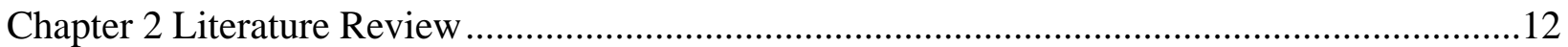

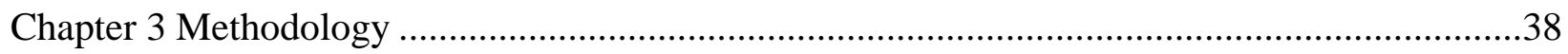

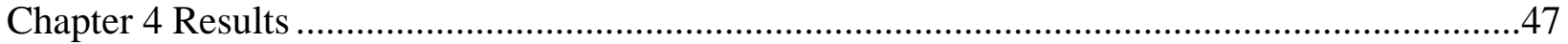

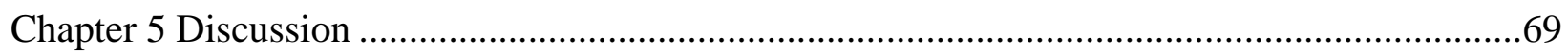

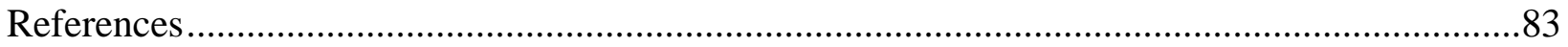

Appendix A Prior Knowledge Assessment....................................................................................

Appendix B Retell Assessment........................................................................................................91

Appendix C Retell Scoring Sheet ............................................................................................

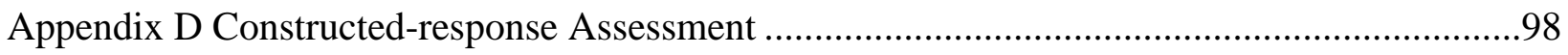

Appendix E Brief-constructed Response Rubric ...........................................................................99

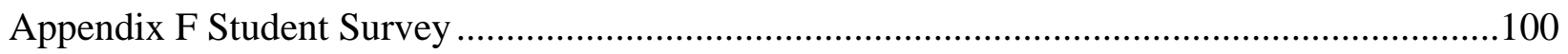




\section{LIST OF TABLES}

Table 1 Descriptive Statistics for the Unaided Retell Based Upon Academic Level and Format of Text......

Table 2 Descriptive Statistics for the Constructed-response Assessment Based upon Academic Level and Format of Text.

Table 3 Numbers and Percentage of Participants Making Predictions While Reading.............59

Table 4 Number and Percentage of Participants Who Self-monitored While Reading

Table 5 Number and Percentage of Participants Who Connected to Prior Knowledge While

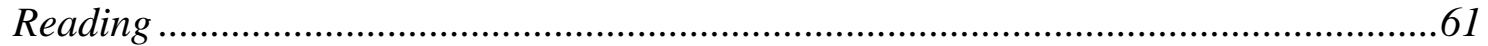

Table 6 Number and Percentage of Participants Who Utilized the WIN Strategy.....

Table 7 Number and Percentage of Participants Who Summarized at the End of Each Section of Text.

Table 8 Number and Percentage of Participants Who Utilized the CPR Strategy.

Table 9 Number and Percentage of Participants Who Utilized Text Features to Increase Comprehension

Table 10 Number and Percentage of Participants Who Read the Summary at the End of the Lesson

Table 11 Summary of Qualitative Findings from the Regression Analyses.

Table 12 Summary of Strategy Use. 


\section{CHAPTER I}

\section{INTRODUCTION AND PROBLEM STATEMENT}

"Ensuring advanced literacy achievement for all students is no longer a luxury but an economic necessity” (RAND, 2002, p. 4). Graduates must be competent at reading and comprehending various formats of high-level text in order to be employable in an ever-changing, competitive workforce. Each element of change that characterizes the workplace today has important implications for the nature of literacy instruction (Leu, Kinzer, Coiro, \& Cammack, 2004). Global economic competition makes learning to read and use information sources more important to success than ever before; therefore, students who cannot read proficiently are at a distinct disadvantage in social settings, as civil participants, and in the working world (Alliance for Education, 2006). As a result, educators face the daunting task of ensuring that every child advances beyond the fundamental literacy skills of the elementary grades to the more challenging literacy demands of the middle and high school years, in an era where new technologies for information and communication are continually redefining what it means to be literate (Castek, Hartman, Leu, Coiro, Henry, \& Zawilinski, n.d.)

\section{Definitions and Characteristics of Literacy}

Leu (2001) asserts that literacy is increasingly deictic, as opposed to being static. In this view, the definition of what it means to be literate is continually evolving as new technologies of literacy quickly emerge in this age of information. Literacy is not merely an end point to be attained but "a process of continuously learning how to become literate” (p. 1). The National Literacy Act of 1991 characterizes literacy as "an individual's ability to read, write, and speak English and compute and solve problems at levels of proficiency necessary to function on the job 
and in society, to achieve one’s goals, and to develop one's knowledge and potential” (as cited in IRA and NCTE, 1996, p.4). The National Council of Teachers of English (NCTE), along with the International Reading Association (IRA) later developed "Standards of English and Language Arts” (1996) which define what students should know about language and be able to do with language. The first standard states the following:

Students read a wide range of print and non-print texts to build an understanding of texts, of themselves, and of the cultures of the United States and the world; to acquire new information; to respond to the needs and the demands of society and the workplace; and for personal fulfillment. (p.25)

Federal mandates prompt further consideration. The No Child Left Behind (2001) legislation includes a list of public policy initiatives, many of which address the issue of reading, as well as technology. According to the NCLB act, 100\% of the nation's students must be proficient readers by the year 2014, as measured by annual assessments in grades three through eight, with an additional assessment administered in grades ten through twelve. The act also addresses technology, stating that we must support every student in crossing the digital divide by guaranteeing that every student is technologically literate by the time the student finishes eighth grade, regardless of the student's gender, ethnicity, race, socioeconomic status, geographic location, or disability. The relationship between technology and literacy is certainly reciprocal in nature and is likely to be even more inseparable in the future.

\section{A Look Back at the History of Literacy}

Literacy and literacy education have changed throughout history in response to changing social contexts and the technologies that these changes often prompted (Leu et al., 2004).

Technology advanced at a rather slow rate in the past; therefore, the changes to literacy occurred 
over extended historical periods. One fact is clear- social contexts, past and present, profoundly shape the changing nature of literacy. Smith (1965) describes how social forces within the United States altered the nature of literacy instruction:

The story of American reading is a fascinating one to pursue. It is a story which reflects the changing religious, economic, and political institutions of a growing and progressive country. This evolutionary progress in reading has been marked by a series of emphases, each of which has been fundamental in nature as to have controlled, to a large extent, both the method and content of reading instruction during the period of its greatest intensity. (p.1)

Smith describes the various periods of reading instruction and explains how each period was shaped by the social forces of the time. She describes literacy and literacy practices focused on religion (1607-1776), nation building and morality (1776-1840), education for intelligent citizenship (1840 to 1880), reading as a cultural asset (1880-1910), scientific investigation and innovations (1910-1935), international conflicts and war (1935-1950), and expanding knowledge and technological revolution (1950-1965).

While the social forces have certainly changed since 1965, we are still in the midst of a technological revolution at a pace never before experienced, as new technologies for information and communication appear continuously. In this light, Leu et al. (2004) describe literacy as a "moving target", continually changing its meaning depending on what society expects literate 
individuals to be able to do. "Definitions of literacy must reflect this moving target" (p.11). It is

evident that definitions of literacy must now include the electronic environment.

\section{Literacy Instruction Today}

As in the past, the social forces today strongly influence and impact education. According to Leu et al. (2004), the social forces that currently impact literacy and literacy instruction include:

- Global economic competition within economies based increasingly on the effective use of information and communication

- The emergence of the Internet as a powerful technology tool for information and communication

- Public policy initiatives by governments around the world to ensure higher levels of literacy achievement, including the use of the Internet and other ICTs

Literacy and literacy instruction have clearly advanced. More recently, they have been changed fundamentally by the advent of the Internet and other forms of information and communication technologies (ICTs), but they have not kept pace with the recent literacy demands. Leu (2001) states, "The pace of this change will be limited only by our ability to manage it. People, not technology, will limit the speed with which new literacies appear” (p. 17). In an age where the Internet has become the defining technology for literacy learning (Leu, McVery, O’Bryne, Zawilinski, Castek, \& Hartman, 2008) reading comprehension is now developing new meanings and new emphases (Duke, 2006). This has provoked researchers and practitioners to seek novel ways of addressing the complexities of reading comprehension (Mokhtari, Kymes, \& Edwards, 2008). Electronic texts that incorporate hyperlinks and hypermedia introduce some complications in defining comprehension because they require skills 
and abilities beyond those required for comprehension of conventional, linear print.

Consequently, literacy educators have been working towards re-conceptualizing literacy in ways that reflect emerging perspectives on the communicative competencies required for $21^{\text {st }}$ century learning, including the ability to read and comprehend electronic text (Hobbs, 2006). According to Karchmer (2001), “It is imperative that students learn new literacies involved in reading electronic text and that teachers incorporate these new media into their curricula so that students learn the skills necessary to comprehend this format of text” ( p. 2).

The construct of new literacies is rapidly gaining momentum in this age of information and technology. "New literacies, whether intentionally or unintentionally, impact literacy instruction in classrooms” (Hahood, Stevens, \& Reinking, 2003; Lankshear \& Knobel, 2003; Lewis and Finders, 2002, as cited in Leu et al., 2004, p.1). This perspective recognizes that a singular label for literacy fails to capture the complexity of the changes that can only be captured by a plural label (Leu et al. 2004). The conceptual framework has varied meanings. To some experts in the field, new literacies are seen as social practices that emerge with new technologies (Street, 2003, as cited in Castek, et al.). Others in the field view new literacies as critical new strategies and dispositions required by the Internet that are essential for online reading comprehension (Coiro, 2003; Leu, Kinzer, Coiro, \& Cammack, 2004, as cited in Castek, et al.). Still others view new literacies as new discourses made possible by the latest technologies (Gee, 2003, as cited in Castek, et al.). To guide their recent work Coiro, Knobel, Lankshear, \& Leu (2008) conclude that most new literacies’ perspectives share the following four assumptions:

- New literacies include the skills, strategies, dispositions, and social practices that are required by new technologies for information and communication.

- New literacies are central to full participation in a global community. 
- New literacies regularly change as their defining qualities change.

- New literacies are multifaceted and our understanding of them benefits from multiple points of view.

A more precise definition of new literacies may never be possible to achieve because the most important characteristic is that they change regularly, and as new technologies for information and communication appear, newer literacies continually emerge (Leu, et al., 2004). It is important to understand, however, that new literacies always build upon foundational literacies, rather than replacing them. Foundational literacies that focus on skill sets such as phonemic awareness, phonics, fluency, vocabulary knowledge, and comprehension will continue to be essential as we move towards the perspective of new literacies.

\section{New Opportunities and New Challenges}

With new opportunities come new challenges for literacy educators. Changing the medium of presentation from print to electronic impacts the ways students learn and may impact their reading comprehension as well (Matthew, 2007). Electronic text can present unique challenges to comprehension, such as dealing with the non-linear nature of hypertext. The Internet provides new formats, new purposes for reading, and new ways to interact with information that can overwhelm students who have been taught to extract meaning from conventional print alone (Cohen, 2006). Lorch (as cited in Waniek, Brunstein, Naumann, \& Krems, 2003) posits that there are no standardized text structure landmarks for hypertext including page numbers, tables of contents, or indexes that could assist with orientation and navigation. This could present a challenge, as students are taught from a young age to use resources, such as text features, found within the informational texts that they are reading. This is 
not always available in the electronic environment, possibly leading to concerns with efficient navigation and ultimately, reading comprehension.

In spite of the challenges, electronic text offers the potential for supporting the comprehension of complex texts. Visuals, graphics, and sound effects can positively impact comprehension (Doty, Popplewell, \& Byers, as cited in Walsh et al., 2001). Kleiman and Peterson (2004) further assert that technology has the ability to direct instruction related to comprehension strategies, including the ability to provide hypertext with embedded prompts asking students to answer questions, provide definitions, explain concepts, and provide visual aids. Additionally, one cannot dismiss the fact that many readers, especially adolescents, are more motivated to read electronic text, as compared to conventionally printed text. Increased motivation often leads to higher levels of student engagement, which can positively impact reading comprehension. Student preferences cannot be ignored and were therefore examined in the present study.

\section{The Purpose}

The primary purpose of this investigation was to explore the relationships between format of text (electronic or print-based) and reading comprehension of adolescent readers. Also in question were potential influences on comprehension from related measures including academic placement of participants, gender, prior knowledge of the content, and overall reading ability. Participants’ reading preferences and self-reported reading behaviors were also considered.

The topic of reading comprehension generally, and electronic text specifically, required further investigation, as the Internet and other ICTs focus heavily on learning from electronic text. Hence, it was imperative to determine if students are prepared for this challenge. Of further concern was the conversion of many high-stakes assessments from print to electronic format. 
Trepidation is grounded in the possibility that students may lack the strategies needed to be successful with assessments in electronic format. Many teachers are fearful that scores may suddenly plummet as a result of the unfamiliar format of the tests. Simply using technology in the classroom does not guarantee that students are obtaining the new literacies needed to be successful during this age of information and accountability. This was cause for alarm and necessitated a call to action.

\section{Rationale}

While there is a significant research base in regard to the reading of traditional text, there is limited research on the nature of reading comprehension on the Internet and other information and communication technologies (Castek et al, n.d.). The nature of reading comprehension has changed, and there is limited research to direct instruction or yield insights pertinent to student comprehension of electronic text. The National Reading Panel (2000) has expressed concern that few studies have explored computer technology and literacy instruction. Additionally, the International Reading Association (2002) has called for "an intensive program of research on literacy and technology issues that will enable us to better understand the rapid changes taking place in the nature of literacy and literacy instruction” (p. 2).

The Educational Testing Service is currently developing assessments for measuring electronic literacy, and the State Educational Technology Directors Association has specified frameworks for assessing technology literacy as outlined in the No Child Left Behind Legislation (Coiro \& Dobler, 2007). At this point, however, not a single state currently administers a reading assessment that measures strategies needed to comprehend electronic text. This is critical because Internet readers construct meaning from their online reading experiences in ways that differ greatly from reading within the pages of a traditional textbook. The RAND Reading Study 
Group (2002) has summarized this issue by stating, “Accessing the Internet makes large demands on individual's literacy skills; in some cases, this new technology requires readers to have novel literacy skills, and little is known about how to analyze or teach those skills” (p.4).

This issue is relevant, as 1.3 billion people now use the Internet regularly (Internet World Stats: Usage and Population Statistics, 2008). In the United States, 87\% of all students ages 12 to 17 use the Internet, with 11 million of them doing so on a daily basis (Lenhart, Madden, \& Hitlin, 2005). This figure has increased by nearly $300 \%$ over the last seven years, and it is projected that more than half of the world's population will be using the Internet within the next seven years. "No previous technology for literacy has been adopted by so many, in so many different places, in such a short period of time, with such profound consequences” (Coiro, et al., 2008, p.19). Clearly, individuals must have the necessary skills to use these information resources, and acquisition of these skills must be a priority for educators.

\section{Research Findings Necessitating the Need for the Present Study}

A growing body of research has been conducted to determine if print or electronic text is more highly comprehended. The research is somewhat inconclusive, thus strengthening the need for further research. While the majority of the literature reviewed for this research, including that of Fry (2007); Alvarez (2006); Joly, Capovilla, Bighetti, and Nicolau (2005); Joly and Lomonaco (2003); and Reinking (1993) report the reading comprehension of electronic text to be superior to comprehension of conventionally printed materials, a study conducted by Matthew (1997) found contrasting results. It is critical to note, however, that several of the studies finding reading comprehension of electronic text to be superior included narration with the text, which is essentially assessing listening comprehension as opposed to reading comprehension. The present study did not include narration or other scaffolds in an effort to obtain a truer depiction of 
reading comprehension. In studies conducted by Dungworth, McKnight, and Morris (2008), Standish (1992), Casteel (1988-1989), Helfeldt and Henk (1985), and Manzo (1985) there were no statistically significant differences in reading comprehension between the two formats of text. Until more research can be carried out that systematically confronts the difference between reading print and electronic text, it will be difficult to move forward in our understanding of how technology expands options for reading and learning from text (Reinking, as cited in Matthew, 1997).

\section{The Present Study}

In this study, seventh graders’ comprehension of print and electronic text was compared to determine which format allowed students to comprehend on a higher level. Regression analysis, using SPSS version 17, served to determine if the format of the text was a significant predictor of comprehension. Prior knowledge of the subject matter, gender, academic level, and overall reading ability were also considered with each format of text. Students’ perceptions and self-reported reading behaviors were explored as well.

These results are important to educators for numerous reasons. Most importantly, websites are gradually replacing printed newspapers, magazines, textbooks, and so forth; therefore, students must be able to read and comprehend electronic text proficiently to function in both the classroom as well as in society. Print has a certain convenience that will ensure that it remains, but "various genres of print are already coming to resemble those of the Web, and each successive generation will need the skills necessary for reading in this environment” (Lemke, 2006, p.4). Students are likely engaging in online classroom activities such as Webquests, research projects, and the like, but most are not being offered explicit instruction or strategies for navigating this type of text. "Literacy educators must recognize the need to respond to the 
changing array of media technologies and resources used in the world outside the classroom in order to make education more responsive to the needs of learners in the $21^{\text {st }}$ century" (Hobbs, 2006, p.15). Because of these implications, the following questions were posed:

\section{Research Questions}

1) What is the relationship between the format of the text and comprehension, as measured by an unaided text retell and constructed- response assessment?

2) What is the relationship between each of academic placement, gender, prior knowledge, and overall reading ability with format of text and any effects on unaided text retell and constructed-response assessment?

3) Which format of text is more highly preferred by seventh grade students?

4) What strategies do seventh grade students report using when reading print and electronic text? 


\section{CHAPTER II}

\section{REVIEW OF LITERATURE}

For most of the last century, the country's attention has been focused on improving literacy education, as American youth must possess strong literacy skills in order to be successful in educational settings, and more importantly, to become productive citizens in the $21^{\text {st }}$ century. The emotional, social, and public health costs of academic failure have been well documented and reported, and the consequences of the national literacy crisis are too serious to be ignored (Alliance for Excellent Education, 2006). The most prevalent deficiency with adolescent struggling readers is the inability to comprehend what is read. As a result, educators are challenged with ensuring that every child moves beyond the basic literacy skills of the elementary grades to the more challenging literacy demands of the middle and high school years. This requires teaching students how to read purposefully and strategically, to integrate new information with prior knowledge, to differentiate between fact and opinion, to recognize causeeffect relationships, and to make inferences based upon what has been read. In short, students must be explicitly taught how to comprehend what they are reading in both print and electronic formats.

\section{Definitions of Reading Comprehension}

The Research and Development Study Group (RAND, 2002) defines reading comprehension as "the process of simultaneously extracting and constructing meaning through interaction and involvement with written language” (p. 11). Included are three basic elements: the reader who is engaged in the comprehension process, the text that is to be comprehended, and the comprehension activity. The reader, the text, and the activity are interrelated in ways that vary throughout pre-reading, during reading, and post-reading activities. The process changes 
over time as the reader matures and develops cognitively, gains experience with more challenging texts, and receives strategy instruction. To comprehend successfully, according to RAND, a reader must possess cognitive abilities and various types of knowledge including vocabulary, domain knowledge, linguistic and discourse knowledge, and knowledge of specific comprehension strategies.

The National Reading Panel purports that "comprehension is critically important to the development of children's reading skills and therefore their ability to obtain an education” (NICHD, 2000, p. 4-1). It is the ultimate goal of successful literacy (Pressley, 2006). Durkin (1993) defines comprehension as "intentional thinking during which meaning is constructed during interactions between reader and text” (as cited in NICHD, p. 4-1). According to this view, meaning resides in the intentional, problem-solving, thinking processes of the reader that occur during an interchange with the text. This is influenced by the text itself, as well as the schema of the reader. Durkin underscores the significance of comprehension by stating, "Reading comprehension has come to be viewed as the essence of reading, essential not only to academic learning but to life-long learning” (as cited in the NICHD, p. 4-1).

Experts in adolescent literacy estimate that as many as $70 \%$ of students struggle with reading in some manner (Alliance of Excellent Education, 2006). Most adolescent struggling readers can accurately decode the words but lack the ability to comprehend what they are reading. Some of these readers lack adequate fluency to facilitate comprehension, while others lack the strategies needed to assist with comprehension. Still others lack a broad vocabulary, intensifying their challenges with text. Additional factors that may account for lack of comprehension include the adolescent reader's emotional and physical states, self-image, and prior knowledge of the topic to be studied (Gill, 2008). 


\section{The Adolescent Reader}

Since the onset of No Child Left Behind legislation, the country's attention has been focused on improving reading instruction. This focus has led to the initiation of reviews, reports, revised curricula, professional development, and provisions to the Reading First initiative (Alliance of Excellent Education, 2006). The attention has focused almost exclusively on early literacy skills in the primary grades. Somewhat neglected has been a focus on comprehension, the core of reading for adolescent readers. Consequently, adolescents and their specialized needs for literacy instruction at the middle and high school level have gone unnoticed by policy makers and the public at large (National Reading Conference, 2006). According to the Alliance of Excellent Education, ensuring adequate literacy instruction for students in the middle and high school years is a more exigent task than facilitating reading instruction in the primary grades for two reasons. First, literacy skills taught during these formative years are more complex in nature, more heavily embedded in subject matter, and more strategy oriented. Second, adolescent readers are not as universally motivated or interested in school-based reading as younger children, leading to lower levels of engagement.

\section{Student Interest and Engagement}

The level of student engagement is the mediating factor through which classroom instruction impacts student achievement. Guthrie and Wigfield's conception of the engagement model (as cited in the National Reading Conference, 2006) calls for instruction that fosters student motivation, strategy use, growth in conceptual knowledge, and opportunities for social interaction with peers. According to McCray, Vaughn, and LaVonne (2001), "We have to be willing to acknowledge that engagement and motivation play an important role in learning and be mindful of the fact that these students need to perceive themselves as doing complex, 
sophisticated work, and work that really challenges them” (p. 28). Thus, the closer literacy activities match students' needs, values, and goals, the greater the likelihood that students will expend effort and sustain interest in them. If students judge literacy activities to be unrewarding, too difficult, or not worth the extra effort because of being peripheral to their interests or needs, they become nonreaders or alliterate adolescents (Alvermann, 2003, as cited in Pitcher, Albright, DeLaney, Walker, Seunarineingh, Mogge, Headley, Ridgeway, Peck, Junt, \& Dunston, 2007) who are capable of reading but choose not to do so (Pitcher et al, 2007.). It is critical that teachers be mindful of the learning characteristics of adolescents and considerate of their need to have topics that are highly relevant to their interests. "Using adolescents' preferred reading materials and modes of instruction will lead to increased motivation, and perhaps to improvements in reading outcomes” (Pitcher et al., p. 379).

Alvermann (2001), in her executive summary to the National Reading Conference (NRC), recognizes the importance of continuing effective literacy instruction beyond the elementary grades. Similar to the Alliance of Excellent Education (2006), the NRC posits that adolescents' interests and needs should be taken into consideration when designing effective literacy instruction at the middle and high school levels. The NRC asserts that in order for academic literacy instruction to be effective, it must address issues of self-efficacy. Adolescents’ perceptions of how competent they are as readers will affect how motivated they are to learn in their subject area classes. Adolescents' interests in the Internet, hypermedia, and other interactive communication technologies suggest the need for educators to teach youth to read with a critical eye toward how writers, illustrators, and the like accurately represent people and their ideas. They must be taught to think critically about various kinds of print and non-print texts. Further, the evolving expertise of adolescents in navigating routine literacy tasks suggests the need to 
involve them in more higher-level thinking experiences that are more student-centered and active in nature, such as opportunities for engaging in project-based and problem-based learning. To be effective, adolescent literacy instruction must be embedded in the regular curriculum and include multiple forms of text that are read for multiple purposes in a variety of learning situations. Unfortunately, according to Pitcher et al. (2007), adolescents are often victims of positioning by schools that have devalued some of the more nontraditional texts, such as electronic text, and instead have valued primarily print-based, content-area texts that students have difficulty comprehending. School reading is based almost exclusively on traditional textbooks, while outof-school reading involves a range of multi-media. These decisions to teach solely from printbased textbooks act as deincentives because they fail to take into account what motivates adolescents to read (Pitcher et al.).

\section{Gender and Literacy}

Addressing the needs of adolescent male readers poses additional problems for educators, as adolescent boys require special attention with respect to literacy (Brozo, 2002). Males dominate remedial reading classes and are more likely to receive special education services for deficits in reading. Specifically, males are three to five times more likely than females to have learning and/or reading disabilities placements in schools (National Center for Education Statistics, 2000). Additionally, they earn lower scores on standardized measures of reading and verbal ability (Pottorff, Phelps-Zientarsky, \& Skovera, as cited in Brozo, 2002). The differences in language acquisition and use of language are two of the most considerable factors that hinder males academically, socially, and emotionally (Slocumb, 2004).

Smith and Wilhelm (2002) provide a summary of the research on gender and literacy. These findings were drawn from the following studies: Abramson and Carter, 1984; Barrs, 1993; 
Children's Literature Research Centre, 1996; Dunne and Khan, 1998; Hall and Coles, 1997;

Kelly, 1986; Maybe, 1997; Millard, 1994, 1997; OFSTED, 1993; Equal Opportunities

Commission and OFSTED, 1996; Shapiro, 1990; Wilhelm, 1997; Wilhelm and Edmiston, 1998;

Wilhelm and Friedemann, 1998. The most compelling findings include:

- Boys learn to read later than girls.

- Boys read slower than girls.

- Girls tend to comprehend narrative texts, and most expository texts, significantly better than boys.

- Boys tend to be better at information retrieval and work-related literacy tasks, as compared to females.

- Boys value reading, as an activity, less than girls.

- Boys have much less interest in leisure reading than girls.

- Boys spend less time reading and express less enthusiasm for reading.

- Boys are more inclined to read informational texts, magazines, newspaper articles, and graphic novels.

- Boys are more enthusiastic about reading electronic texts, as compared to girls.

- In a study conducted by Oakhill and Petrides (2007), reading comprehension was compared for males and females, aged 10 and eleven. Participants read two selections; one was about spiders and the other was about World War II. The majority of males stated they would prefer reading about spiders, while the females stated a preference to reading about the evacuation of children during World War II. These patterns of preference were reflected in the children's performances on the comprehension assessments. Whereas the males' comprehension was directly correlated to their preference of topic, the females’ performance was not influenced 
by their preferences. The effect of interest was even stronger for poor comprehenders.

Additionally, females were more likely to continue reading, even with lower- interest reading selections. This supports the view that "topic interest is related to affective response, which increases persistence, and, thereby, learning” (p. 232). These findings supports those of Asher and Markell, along with Anderson, Shirey, Wilson, and Fielding (as cited in Oakhill and Petrides, 2007) who found that there was increased comprehension and recall ability from texts that the children expressed a particular interest in reading, and that effect was more pronounced for male students. An earlier study by Bernstein (also cited in Oakhill and Petrides) examined the relationship between interest and reading comprehension and found that high interest resulted in superior comprehension, as well as greater reading speed.

\section{Prior Knowledge}

Reading comprehension is undoubtedly a multi-faceted construct influenced by, among other things, prior knowledge (Clark, Kamhi, Wasco, \& Jones, 2008). Many of the current ideas about comprehension have been based on the schema theory (McCormick, 2007), which suggests that what a reader already knows, or does not know, about a topic can greatly influence comprehension. This notion was originally purported by Bartlett (1932) and later by Anderson (1977), Rumelhart (1981), and others. The theory suggests that when readers recognize words on a page, they think and react based on their prior knowledge, or schemata. Readers work to integrate information in the text with what is already known in a quest to facilitate meaning. Sometimes this is accomplished rather unconsciously, and at other times, a focused effort is required. Regardless, it is a proper entry point for instruction (Kujawa \& Huske, 1995) if we expect to elevate levels of comprehension. 
Key Elements of Effective Adolescent Literacy Programs as Reported by the Reading Next Panel

Simply stated, adolescents' literacy skills are not keeping pace with the societal demands of living in an information age that is changing rapidly and shows no signs of slowing (Alvermann, 2001). To address this reality, educational leaders have committed themselves to improving reading achievement. Researchers are currently focused on defining instructional strategies that can accelerate learning for adolescents who struggle with fundamental reading skills. Consequently, the Reading Next Panel (Alliance of Excellent Education, 2006) established a list of key elements of effective adolescent literacy programs. Included in the list of instructional improvements is direct, explicit comprehension instruction. Approaches for instruction include comprehension monitoring and metacognition instruction, teacher modeling, scaffolding instruction, and comprehension strategies instruction. Teaching and modeling these approaches with adolescent readers is vital if they are to understand the meaning behind what they are reading. This is especially critical during the middle and high school years when the reading of text becomes increasingly challenging and students' motivation tends to diminish. Also included in this list of key elements of effective literacy instruction is a technology component, used as both a tool for and a topic of reading instruction. "If we don't have materials, ideas, concepts, and text that are engaging to students, the likelihood that they will practice skills is low. That is why you really need to have both explicit, systematic instruction and motivating, high-interest text for students to be successful” (McCray et al., 2001, p. 28). 
The Text

\section{Strategy Instruction for Text Comprehension}

Proficient readers normally acquire strategies for active comprehension through informal means (NICHD, 2000). The National Reading Panel (2000) contends, however, that explicit or formal instruction in these strategies leads to improvement in text understanding and information use. The eight types of strategy instruction that appear to be most effective for classroom instruction of text comprehension, as identified by the Panel, include the following: comprehension monitoring, cooperative learning, graphic and semantic organizers, story structure activities, question answering, question generating, summarization, and multiplestrategy instruction. Subsequent to analyzing the findings of 203 research studies, the Panel asserts that when students are given explicit strategy instruction and read conventional print text, they make significant gains on measures of reading comprehension.

\section{Text Features}

In addition to comprehension strategies, the features of the text, as well as the medium of the text, have a tremendous effect on comprehension.

The proliferation of electronic text, with its unique characteristics, has led to broadening the definition of text to include the digital medium. Today the definition of literacy has expanded from traditional notions of reading to include the ability to learn, comprehend, and interact with technology in a meaningful way. (Coiro, 2003, p.74)

The Internet provides new formats, new purposes for reading, and new ways to interact with information that can overwhelm students who have been taught to extract meaning from conventional print alone (Cohen, 2006). Changing the medium of presentation from print to electronic impacts the ways students learn and may impact their reading comprehension 
(Matthew, 1997). As Sutherland-Smith (2002) states, “The Internet does not represent an alternative better than books; it signifies an option that is different from books” (p. 668).

According to Duke, Schmar-Dobler, and Zhang (2006), skilled hypertext readers utilize a number of comprehension strategies including the following: setting a purpose for reading, activating prior knowledge, previewing, predicting, attending to text structure and main idea, evaluating the text and text information, and monitoring. These are some of the same strategies that skilled readers use when reading conventionally printed text. Proficient readers seem to have the ability to transfer their print text reading strategies to the computer environment. Researchers have found, however, that in addition to the strategies used to read print text, additional strategies must be utilized when reading electronic text, such as those explained by Sutherland -Smith (2002) and Cohen (2006).

Sutherland-Smith (2002) advocates that educators must explicitly teach strategies to aid students in comprehending electronic text. She asserts that students must be taught the "snatchand-grab” technique in which the aim is for students to read superficially, with limited comprehension of the complete text, and compile a grab-bag of references in which to later refer. She also coined the term "chunking technique" to show students the ways in which a complex topic could be broken down into manageable sections. She further suggests that students be provided clear search guidelines and limited links, with shortcut lists to sites and search engines. Once on the Web, they must be taught to evaluate the non-textual features of the text, such as images and graphics. Although this list of strategies is not exclusive, they are strategies that have proven to be successful with Sutherland-Smith’s sixth grade students.

Cohen (2006) also asserts that students should be taught new literacies to fully comprehend electronic text. She states that readers must be taught to self-monitor constantly 
when reading interactive texts to ensure that they comprehend the meaning of the text. They must determine what their role is in the interactive process and if they feel comfortable in contributing to the interaction. She also states the importance of students incorporating visual literacy skills to interpret page layout, read graphs, navigate hyperlinks, and understand frames and pop-up windows. Further, she suggests that students use graphic organizers to record and synthesize information that they find from multiple sites.

\section{Challenges Associated with Reading Electronic Text}

Electronic text can present distinctive challenges to comprehension, such as dealing with the non-linear nature of hypertext. Students must employ a new type of inferential reasoning to read proficiently in this medium. According to Duke, Schmar-Dobler, and Zhang (2006), hypertext comprehension requires that the reader take an active role in text construction by forcing decisions about where and what to click. There is a heightened emphasis on decisionmaking on the part of the reader. Web literacy involves expanding critical reading skills to incorporate evaluation of visual and non-textual features. Coiro and Dobler (2007) explain that traditional textbooks are carefully edited and contain words and images that provide accurate facts, while Internet texts are not as carefully edited and can deceive young readers who may not have the acquired skills to critically evaluate the information in which they are reading. Further, the Internet requires readers to sift through multiple sources of information, which is more complex in this format, and synthesizing electronic information can be challenging for both experienced and inexperienced readers.

\section{Differences in Reading Electronic and Print Text}

The fact that any printed text can be represented on a computer screen may lead to the conclusion that there is no substantive difference between reading print and electronic text, but 
this conclusion is only accurate on a superficial level (McKenna, Reinking, Labbo, \& Keiffer, 1999). According to Reinking, (as cited in McKenna et al., 1999), there are four profound differences between print and electronic text that influence the nature of reading. First, electronic text is truly interactive in that it can be altered in response to reader input. Second, the reading of electronic texts can be guided by teachers or software developers in order to increase comprehension. Third, electronic texts are often structured far differently than their print counterparts, often containing hypertextual networks and multimedia. Finally, electronic texts add to the range of symbols available to readers and writers, which may be in the form of icons or multimedia presentations. These qualities, according to Reinking, present readers with a potentially challenging set of choices, which are compounded when students are linked to the World Wide Web. Students must recognize that reading is not simply reading from the first word to the last of a fixed, linear text. "It must become a strategic process of satisfying one’s purpose, a goal that is desirable in conventional texts but essential in hypertext (Reinking, as cited in McKenna et al., 1999, p. 112)

Members of the New Literacies Research Lab, including O’Byrne, Zawilinski, McVerry, and Leu (Mokhtari, Kymes, \& Edwards, 2008) contend that online and offline reading comprehension is not the same. Online reading comprehension is almost always a problemsolving process that begins with a question and takes place within a limitless information space. In the Lab’s view, online reading comprehension skills cluster around 5 areas: reading online to generate a problem or question from one’s social context, reading to locate information online, reading to critically evaluate information, reading to synthesize online information from multiple sources, and reading to communicate and exchange information with others. 
Sutherland-Smith (2002), as previously mentioned, engaged in a qualitative research study with sixth grade students and learned that students do perceive Web text reading as different from print reading. One student indicated, "On the Internet, you have to be really quick, and you can go lots of places to find out heaps of stuff, but with books, you need to go slower” (p. 664). Similar comments indicated that other students also felt that there was a necessity for speed on the Internet. According to Sutherland-Smith, there was almost a "snatch- and- grab" philosophy adopted by students reading Web text that was not apparent when students read print text. Students expected immediate results when conducting Web searches; however, there was not a similar expectation for print text. Students also indicated that they preferred the images on the Web, which they saw as more "life-like" than static images in printed material. In spite of this, students in this study questioned the authority and authenticity of Web text and images, which they did not question when reading print text.

Bartlett (n.d.) also conducted a study with sixth grade students to ascertain if her students possessed the necessary skills to be successful when reading electronic text. She questioned if her students knew how to navigate using hypertext, from one hyperlink to the next, and was curious to know if they would get so distracted when moving from link to link that they would fail to comprehend the material. From her observations, she identified several critical differences between the reading of print text and electronic text. She asserts that a reader generally sees less text presented at a time when reading hypertext on a computer than a reader would likely view on a page of a traditional book. This is advantageous for the reader. With hypertext, there is not usually a clear beginning and ending to the text as there is with print text that reads in a more linear fashion. Readers of print text rely solely on the author to indicate a logical progression of ideas through the use of subheadings, bold print words, and transitional phrases, but in the 
hypertext format, there is not always a given order to the information provided. "This requires the reader to insert him/herself into the text and to construct meaning from it. The reader gains a new authority that he/she does not have when reading traditional print material.” (p.2).

Bartlett’s (n.d.) observations indicate evidence of students using reading practices appropriate for electronic text. These include the following: looking at all parts of the screen and making note of significant captions, moving the cursor with the mouse to prevent losing one’s place while reading the text on the screen, using the "back" button to refer to an earlier page, and asking questions of the teacher for clarification of certain sections of the reading. These reading strategies enabled the students to stay engaged, be highly motivated to complete the task, and comprehend the material successfully. One student commented, "When I read a book, I get bored, and I want to fall asleep. When I am on the computer, I do not want to fall asleep” (p. 2). All of the students in the study echoed this sentiment; they preferred electronic text reading. This motivation led to higher levels of student engagement throughout the project, and there was a distinct correlation between engagement and achievement.

Because the environments of students today are filled with electronic texts, researchers contend that there needs to be a pedagogical shift so that classroom instruction incorporates these new modes of reading and communication (Walsh, Asha, \& Spraigner, 2007). Research is in the early stages of determining the exact features needed for reading electronic texts and determining how the reading process is similar to or different from reading print text (Walsh, 2006, as cited by Walsh et al., 2007).

\section{Advantages and Disadvantages of Reading Electronic Text}

Walsh et al. (2007) report that reading electronic text has advantages as well as disadvantages. One advantage of electronic text reading is that children are more in control of 
their learning (Davis \& Pearman, 2005, as cited in Walsh et al., 2007). They determine their own courses of action and have increased control over their learning. This is motivating for the readers, leading to higher levels of engagement. Additionally, visuals, graphics, and sound effects can positively impact comprehension, as they can assist with prediction, comprehension, and vocabulary knowledge (Doty, Popplewell, \& Byers, as cited in Walsh et al., 2001). Kleiman and Peterson (2004) assert that technology has the ability to direct instruction in comprehension strategies, including the ability to provide hypertext with embedded prompts asking students to answer questions, provide definitions, explain concepts, and provide visual aids. Because of this, readers can often read successfully without the assistance of a parent or teacher, as the technology provides the needed scaffolds to assist with comprehension.

There are disadvantages associated with reading electronic text as well. The greatest disadvantage is the current lack of explicit strategy instruction for this medium of text, such as those advocated by Leu, et al. (2004), Bartlett (n.d.), Sutherland-Smith (2002), and Cohen (2006). Other disadvantages of reading electronic text, as expressed by Walsh et al. (2007) include children becoming too dependent on electronic features for decoding, becoming distracted by features that are not relevant, and experiencing frustration with electronic features if there is a delay in the transfer of electronic pages. Lorch (as cited in Waniek, Brunstein, Naumann, \& Krems, 2003) states that there are no standardized text structure landmarks for hypertext including page numbers, tables of contents, or indexes that could assist with orientation and navigation. This could present a challenge, as students are taught from an early age to use resources found within the informational texts that they are reading. This is not always available in the electronic environment, possibly leading to concerns with efficient navigation. 
Some research suggests that difficulties experienced by struggling readers are compounded when reading electronic text (Coiro \& Dobler, 2007). In this view, less skilled readers tend to lack prior knowledge and interact more passively with this type of text. As a result, readers are unsure as to where to focus their attention and are unable to use alternative strategies if they do not know for what they are searching. Electronic text demands higher levels of intellectual reasoning and comprehension monitoring strategies that assist readers in staying on task. These are the areas in which struggling readers tend to lack the necessary strategies to be successful readers; therefore, electronic text might be more challenging to comprehend than conventionally printed text for those who have reading deficits. Conversely, McKenna et al. (1999) contend that electronic text, with its emerging set of supports, may help to compensate for inadequate reading ability. For example, there are electronic resources available that offer access to various information sources including encyclopedias, dictionaries and databases. Illustrative resources provide the reader with examples, comparisons, and visualizations that are not part of the linear text. Resources for summarizing provide overviews or outlines of the text. Notational resources allow the reader to take notes on an electronic clipboard when reading. McKenna et al. assert that while struggling readers must acquire the skills necessary to take advantage of these resources, teachers should not shelter the readers by exposing them only to print text. "We argue that the cost-benefit ratio of introducing troubled readers to electronic texts overwhelmingly favors their use" (McKenna et al., p. 114).

Zumbach and Maryam (2008) discuss cognitive overload relative to reading electronic text. Their analysis is based on different types of cognitive load, the dimensions of linearity/nonlinearity, as well as text characteristics. In their study, sixty participants completed a computerbased learning program that contained a narrative text and an encyclopedia text in either linear or 
non-linear presentation format. Results of the study confirmed that non-linear information presentation of narrative text increases cognitive load and decreases knowledge acquisition. They assert that learners have to process information represented in hypertext nodes and plan their further navigation simultaneously, which demands higher levels of working memory. Learners using a sequential, almost linear information retrieval, show higher levels of comprehension than participants using the non-linear browsing strategy. Because of this, reading electronic text that contains hyperlinks might lead to cognitive overload, which will subsequently impact reading comprehension in a negative manner.

Kleiman and Peterson (2004) also believe that the multifaceted requirements of the reading process can lead to cognitive overload, in which there are too many competing demands for the child to succeed in reading fluently with comprehension. However, in contrast to the viewpoints of Zumbach and Maryam (2008), Kleiman and Peterson assert that computers can provide powerful scaffolds, or "training wheels" as the authors call them, to assist children in becoming successful readers and overcoming this cognitive overload that students might experience when reading conventionally printed text.

\section{Research Findings}

Dungworth, McKnight, and Morris (2008) investigated the interaction between children and electronic storybooks. The purpose of the study was to examine to what extent children read electronic and print books, and whether the medium of presentation affects comprehension and enjoyment of reading. Two different stories were read by 132 children between the ages of 9 and 10. Of the participants, 51 children read an excerpt from The Magicians of Caprona, with about half reading an electronic version containing an online dictionary and the remainder reading a printed version with a separate printed dictionary. The remaining 81 children read an excerpt 
from The Little Prince, with 26 children reading an electronic version of the story, and 26 children reading the same electronic text with added narration. Twenty-nine students read the storybook in print form without a dictionary. Findings from interviews revealed that the type of medium did not significantly affect the children's enjoyment of either storybook, as there was no correlation between students' preference of text format and comprehension. Comprehension was assessed by multiple choice and short answer questions designed to determine the children's ability to extract facts and make inferences based on the text. Students were permitted to access the text when answering the questions to ensure that comprehension, as opposed to memory, was being assessed. Findings revealed that there was no statistically significant difference in comprehension scores for electronic and print text. For both types of text, comprehension scores were higher for retrieval type questions as compared to questions in which students were required to make inferences. Scores were most likely higher on basic recall questions because the students were able to employ look-backs when answering questions. For the inferential questions requiring higher-level thinking skills, look-backs would not be as helpful. The provision of narration in the electronic version of The Little Prince led to significantly higher comprehension scores than when narration was absent, most likely because the students' listening comprehension was proficient. Reading comprehension and listening comprehension are not synonymous, as they are measuring different aspects of comprehension. Students who cannot decode words, or understand the meaning behind the words, could have been successful in the story that was accompanied with narration. Finally, the use of the online dictionary in the electronic selection of The Magicians of Caprona was significantly greater than that for the printed dictionary in that condition. This finding parallels that of Fry (2007); Alvarez (2006); and Reinking (1993). 
Fry (2007) conducted a study to investigate how middle school students’ comprehension is impacted when reading electronic social studies text containing a pop-up dictionary feature. One hundred and twenty-nine students from grades six, seven, and eight participated in the study, in which three forms of text were read by each student: print text from the students' grade level social studies textbook, electronic text that was created to be similar to the print text from the social studies textbook, and electronic text with a pop-up dictionary feature. After reading each type of text, students were given a two part comprehension assessment. Part A of the assessment consisted of multiple choice test items, while Part B consisted of cloze test items. Findings revealed that the pop-up dictionary reading method, available with the electronic text, was shown to be statistically better than the print text reading method, suggesting that the pop-up dictionaries may increase middle school learners’ reading comprehension. Student use of the electronic dictionary was measured in two ways. First, the researchers and their assistants wrote anecdotal records while observing student use of the dictionary. They noted that struggling readers used the dictionary extensively, while the proficient readers rarely used this feature. Sixth and seventh grade students accessed the dictionary far more frequently than the eighth graders. Additionally, students were asked to complete a questionnaire on which they indicated the extent to which they used the pop-up dictionary. The students' self-reports of dictionary use confirmed what was recorded on the anecdotal notes: struggling readers accessed the dictionary more frequently that students who read proficiently.

Alvarez (2006) conducted multiple studies aimed at evaluating the comprehension of print and electronic texts. Each of the experiments involved the same 40 children, ages 11 and 12, who were enrolled in the sixth grade at a private school located in Medellin, Colombia. The experiments addressed the following question: "When reading digital and printed texts, do 
differences occur in readers' utilization of the dictionary, contextual analysis, the content and quality of semantic maps, the qualities of summaries produced, and the recall of main ideas?” Findings revealed that in all 5 of Alvarez's experiments, the students who were assigned to read electronic text outperformed those reading print text at statistically significant levels. Specifically, participants reading the electronic version of the text investigated more word meanings in the dictionary as compared to those reading print text. This finding also held true in the studies conducted by Dungworth et al (2008), Fry (2007), and Reinking (1993). Semantic maps developed by readers of electronic text were of higher quality, as assessed by a rubric, as compared to those developed by the readers of print text. Additionally, readers of electronic text were better able to identify main ideas statements and were able to produce higher quality summaries of the text. The results of Alvarez's experiments clearly indicate that readers' comprehension of the electronic texts, as designed for this study, consistently surpassed readers of conventionally printed information. This conclusion held for competent as well as less competent readers. However, the authors of this study wanted it to be known that the scope of the aforementioned study is relatively small, and the findings have not been published in any peer-reviewed outlets. Therefore, readers should not cite these studies in literature reviews without these important caveats.

Joly, Capovilla, Bighetti, and Nicolau (2005) conducted a study in which they evaluated the reading comprehension of 80 freshman psychology students reading journalistic text in both print and electronic formats. Students first read conventionally printed text and then responded, in writing, to three content interpretation questions. A week later, they were asked to read and respond to an electronic newspaper article in linear format. Findings revealed that comprehension was superior for electronic text. Females demonstrated higher reading 
comprehension than males in both text formats, and participants under the age of twenty-five achieved at a higher level when reading electronic text. It is important to note that there were no hyperlinks embedded in this linear reading. Instead, the print on the screen closely paralleled that of the print text in hard copy. The findings of this study concur with a study conducted by Joly and Lomonaco (as cited in Joly et al., 2005) in which 80 Brazilian students in grades one to four comprehended electronic text at a higher level, as assessed by Cloze procedure. In this procedure, words were deleted from a passage and students were asked to insert words that made sense in the sentence to demonstrate that they were constructing meaning from the text.

Matthew (1997) reports on two experiments designed to study the impact of electronic text on the reading comprehension of third grade students. The first experiment involved 37 matched pairs of students reading either CD-ROM or print versions of the same books. Findings revealed that although their scores were not significantly higher, students who read the print versions of the text had higher mean comprehension scores, when measured by open-ended questions, as compared to those reading electronic text. According to Matthew, it is possible that the static print text and unchanging illustrations facilitated the cued recall of information measured by the open-ended questions. Perhaps the novelty of the technology was somewhat of a distraction and students were more accustomed to reading print text. There was a statistically significant difference, however, in reading comprehension when measured by story retellings, as students in the group reading the interactive CD-ROM version of the stories scored significantly higher on retells than those reading print text. In Experiment 2, the 30 students who read the print stories in Experiment 1 read two additional stories in CD-ROM format. Their comprehension scores were significantly higher when reading CD-ROM stories, again as evidenced by story retellings. Matthew suggests that this was possibly due to the interactive 
nature of the stories on CD-ROM. It is critical to note that students reading electronic text were able to click on words to obtain pronunciations and definitions, as well as click on pictures for narration. Because of the narration, true reading comprehension was not assessed; listening comprehension was assessed instead.

Studies cited by Matthew (1997) including that of Standish (1992), Casteel (1988-1989), Helfeldt and Henk (1985), and Manzo (1985) found no statistically significant difference when comparing students reading each text type. Stine (1993); Wepner, Feely, and Minery (1990); and Reinking and Schreiner (1985) found that students who read electronic texts had significantly higher comprehension than those reading print text. Miller, Blackstock, and Miller (1994), and Harper and Ewing (1986) compared the reading comprehension of the same students and found that the students did, in fact, have increased comprehension when reading electronic text.

Reinking (1993) conducted a study in which middle school students read two short passages adapted from a science text. He found that students reading the electronic text investigated more meanings of vocabulary words, were able to recall the meanings of more words, and comprehended electronic text at a higher level. He asserts that electronic text can affect literal interaction between readers and texts, whereas readers and print texts cannot literally interact. He suggests that "becoming literate for electronic reading and writing will require the readers and writers to become acquainted with the nonlinear, non-sequential text structures that are the natural form of electronic text” (Reinking, 1993, p.1). He further suggests that educators will need to develop appropriate strategies for reading and writing such texts. Because of this, he advocates for educators and policy makers to redefine literacy to include the reading and writing not only of printed texts but of electronic texts as well. “As educators look for new ways to assist children in becoming literate, and as electronic technology becomes more 
advanced and more available, expanding our ideas about what it means to be literate seems almost inevitable” (p. 1).

\section{Discussion}

It would appear that the research on reading comprehension of print and electronic text is somewhat inconclusive, thus strengthening the need for further research. The most recent study conducted by Dungworth, McKnight, and Morris (2008) found no statistically significant difference in comprehension scores between those reading print text and those reading electronic text. Matthew’s (1997) study produced similar results when the participants’ reading comprehension was assessed with open-ended questions; however, scores for electronic text were higher when the participants were assessed through retell measures. Studies conducted by Standish (1992), Casteel (1988-1989), Helfeldt and Henk (1985), and Manzo (1985) also found no statistically significant difference when comparing students reading of each format of text. These findings could be a direct result of students using the strategies that they know to be successful with print text and applying those same strategies when reading text in electronic format. Many of the strategies are the same, allowing for this transfer of skills to the electronic environment. Other strategies may need to be slightly modified or altered to work in the electronic environment, and readers are most likely learning these strategies incidentally.

Fry (2007); Alvarez (2006); Joly, Capovilla, Bighetti, and Nicolau (2005); Joly and Lomonaco (2003); and Reinking (1993) found that comprehension is higher when reading electronic text. This finding was true for children as young as first grade and held true for college students. It was true in relatively recent studies, as well as studies published over fifteen years ago. Although many teachers are not explicitly teaching children the strategies necessary to competently read electronic text, many are learning these strategies incidentally as a result of the 
vast amount of time spent using computers during their leisure time. Their experiences with reading and interacting with electronic text, on a daily basis, most likely had a positive impact on the students' comprehension. There is increased interaction between the reader and the text in this medium of reading, which may keep the reader more highly engaged in the reading and more motivated to want to read. Additionally, electronic texts can capture students' attention and stimulate their imaginations. This mixture of visual, tactile, and listening modalities enables students to learn through their preferred modality (Matthew, 1997). Finally, the use of online dictionaries possibly contributed to these findings. Studies conducted by Dungworth et al (2008), Fry (2007), Alvarez (2006), and Reinking (1993) revealed that students used dictionaries more often when reading electronic text. Because vocabulary knowledge is closely correlated to comprehension, use of the dictionaries could possibly have been a contributing factor in the higher comprehension scores in these studies. According to Baker, Simmons, and Kame'enui, (2004) the extent of the reader's vocabulary knowledge is directly related to the depth of comprehension they will derive from text.

Few studies found the comprehension of print text to be superior. Although this was the finding of the Matthew (1997) study, it was not at a statistically significant level. Because most classroom instruction in comprehension focuses on the use of conventionally printed text, these findings could be surprising to many classroom teachers. Teachers routinely model researchbased comprehension strategies, many of which can be applied solely to conventionally printed text. Most curricula do not require or take into consideration strategies for reading and comprehending electronic text. Yet, as evidenced in the aforementioned studies, this does not appear to make a difference in regard to comprehension levels. However, it is important to highlight that many of the electronic texts discussed in this literature review included narration of 
the text. Because of this, one has to question if reading comprehension was truly assessed or if listening comprehension was instead assessed. It would be beneficial to educators if a study was conducted that measured reading comprehension of authentic electronic text without narration and without dictionaries or other scaffolds. A study that incorporates authentic text, likely to be read in people's everyday lives, would be of greatest value.

Research is contradictory in regards to less competent readers having the ability to proficiently read and comprehend electronic text at a superior level. Coiro and Dobler (2007) predicted that difficulties experienced by struggling readers may be compounded when reading electronic text, while the results of Alvarez's (2006) experiments would indicate otherwise. The less competent readers who participated in this study read electronic text more proficiently, as evidenced in all five experiments that were conducted. Zumbach and Maryam's (2008) theory of cognitive overload when reading hypertext did not seem to apply to these studies. Rather, Kleiman and Peterson's (2004) assertion that computers can provide powerful scaffolds to assist children in becoming successful readers and overcoming this cognitive overload may be more accurate. From the findings of numerous studies, the electronic dictionaries were frequently accessed, providing a form of scaffolding for the readers. Technology is being infused in many literacy programs today as both a facilitator of literacy and a medium of literacy. It should be used as both an instructional tool and an instructional topic (RAND, 2002). The dictionary feature is one instructional tool that appears to assist readers in comprehending electronic text.

A significant base of research, developed over many years, is available to inform educators about effective approaches to teaching children to read. However, research on the use of multimedia digital technologies to enhance reading instruction is in its infancy. According to Cohen (2006), it is imperative that students learn new literacies involved in reading electronic 
text and that teachers incorporate these new media into their curricula so that students learn the skills necessary to comprehend electronic text in the 21st century. "In a world in which the Internet has become this generation's defining technology for literacy and learning, we will require bold new thinking to reconceptualize our field (Castek et al., n.d.). 


\section{CHAPTER III}

\section{METHODOLODY}

The primary purpose of this research study was to investigate the relationship between the format of text and seventh grade students' reading comprehension. Through this study, print and electronic texts were compared in an effort to determine which format, if either, led to higher levels of comprehension. Of secondary interest were other co-variables that could influence comprehension including prior knowledge of the subject matter, gender, students’ academic placement, and overall reading ability. Participants’ self-reported perceptions and reading behaviors were also explored.

\section{Participants}

All 180 seventh grade students at Western Middle School, located in western Maryland, were invited to participate in this study. An explanation of the study, attached to consent and assent forms, was distributed to each student. Consent/assent forms signed by students and their parents were collected from 130 students, representing a return rate of $72 \%$, in this convenience sample. One hundred and twenty-seven students actually participated in the study, with representation from each of the following academic placements: Honors $(n=36)$, Merit $(n=52)$, General ( $n=30)$, and Special Education ( $n=7)$. Students' academic placements were determined by the school administration prior to the beginning of the 2008-2009 school year and were based upon Maryland School Assessment (MSA) scores, Gates-MacGinitie Reading Test scores, and teacher recommendations. Students in the honors track consistently engage in challenging assignments and work within a somewhat compacted curriculum. A large proportion of these students scored within the "advanced” range on the MSA in both reading and mathematics. Merit level students are working on grade level and are considered to be college-bound. The majority 
of these students earned "proficient” status on the MSA. General level students often perform below grade level on classroom assignments and assessments. Many of these students struggle in the core academic classes, either because of deficits in reading or lack of motivation. A notable percentage of these students scored within the "basic" range on the most recent MSA. Special education students have been identified through educational and ability testing and have individualized education plans (IEPs). With accommodations and modifications, many of these students scored at the "proficient" level on the MSA, while others earned a "basic" score.

By including students from each of the academic levels, I, as researcher, was able to determine the format of text more highly comprehended by each level of students. This information was important to me, as I am currently supervising a new reading intervention program, known as Voyager, that incorporates a fair amount of electronic text reading, and I wanted to know if the increased exposure to electronic text correlated with higher comprehension scores in this format of text, or if students claim a preference for this type of text. I was also eager to determine if students embedded the strategies learned through this program and applied them when reading the assigned text. The results yielded from this study will be especially useful for the teachers as they make instructional decisions for the 2009-2010 school year, including the academic placement of the students.

\section{Research Context}

\section{Western Middle School}

Located in the scenic mountains of rural western Maryland, Western Middle School (henceforth known as WMS) is one of two middle schools in the county. The student population of WMS is comprised of 590 students, from six elementary feeder schools, representing eight distinct communities. While there is very little racial or ethnic diversity within the school and 
community, there is great diversity in socioeconomic status. Fifty-two percent of the student population is eligible for free and reduced meals, while a substantial portion of the students live in affluent households. This economic disparity is not a factor with student achievement, however, as the free and reduced meals students (FARMS) are now performing at essentially the same level as their peers, as evidenced by scores on the Maryland School Assessment. Additionally, the male students are now performing only slightly below their female counterparts, despite the fact that this is in contrast to the national trend on gender and academic achievement. The special education cell is the area of greatest weakness, yet the school has managed to make Adequate Yearly Progress (AYP) in this cell as well.

The Researcher's Role

As researcher in this study, I wear many hats within a typical school day including that of instructional leader, reading specialist, and classroom teacher. My classroom responsibilities include teaching language arts and social studies to general level seventh grade students, as well as teaching language arts to sixth grade students who receive special education services. Both groups of students currently participate in the Voyager reading intervention program. The school's administration made a decision to place all general and special education students in this intervention program, which is designed for struggling readers who are reading one to two years below grade level. Many general level students in the program are reading only slightly below grade level, or on level, but have been targeted for the program as a result of earning a "basic" score on the Maryland School Assessment or due to lack of motivation in reading, as reported by their classroom teachers. 


\section{The Voyager Reading Intervention Program}

The newly-implemented reading intervention program, known as Voyager, was well received by both the students and staff at Western Middle School. One aspect of the program that is particularly motivating and engaging for the students is the high-interest, differentiated electronic text reading that occurs twice in each ten day expedition. Voyager participants are the only students in the school with weekly opportunities to read electronic text during the language arts block. The students read a combination of both electronic and print texts, representing various genres, and then complete weekly assessments in both electronic and print format. A noticeable trend that The Western Middle School staff discovered while disaggregating data is that the majority of the general level students performed at higher levels on the electronic assessments that follow the electronic readings, as compared to scores on the written assessments that follow the reading of conventionally printed text. Conversely, the trend with special education seemed to indicate that students performed at higher levels on the traditional, written assessments after reading conventionally printed text. Both forms of the assessments measured vocabulary and comprehension. These trends were constant across grade levels and in all eight classrooms that utilized the Voyager program. It was these trends, along with findings contained in the Literature Review, that contributed to my growing interest in this topic, leading me seek answers to the following questions:

\section{Research Questions}

1) What is the relationship between the format of the text and comprehension, as measured by an unaided text retell and constructed response assessment? 
2) What is the relationship between each of academic placement, gender, prior knowledge, and overall reading ability with format of text and any effects on unaided text retell and constructed-response assessment?

3) Which format of text is more highly preferred by seventh grade students?

4) What strategies do seventh grade students report using when reading print and electronic text?

\title{
Research Design
}

This study employed a concurrent explanatory research design following suggestions by Creswell and Plano-Clark (2006). The components of the study consisted of regression analyses, employing a general linear model, and a survey of student perceptions and reading behaviors. The first component of this study sought to determine if a predictor variable (format of text) and four potential co-variables (academic placement level, gender, prior knowledge, and overall reading ability) had an impact on the criterion variables (unaided retell and constructed response assessment). Regression analysis served to measure these relationships, making use of regression tools in SPSS, version 17 . The second component of the study was comprised of a reading behavior survey intended to explore potential causal factors that may have influenced the regression models.

\author{
Materials and Instrumentation
}

\section{Materials}

\section{Conventionally Printed Text}

The conventionally printed text used in this study was a four- page lesson from Chapter 23 of World History (Holt, Rinehart, \& Winston, 2006) titled “World War II”. According to the Fry Graph Readability Formula, the textbook has a readability level of ninth grade. The lesson 
included 14 paragraphs of narrative, as well as photographs of the war leaders, a diary entry of Anne Frank (primary source), a cause-effect chart, and a short summary at the end of the chapter. Traditional questioning on the constructed response assessment was based on these text features. Vocabulary words were printed in bold type, with definitions highlighted in yellow. Major headings were showcased in blue font, while minor headings were printed in red font. There was also a short summary at the end of the lesson. Because all seventh grade students regularly use this textbook, participants were familiar with the text, including its layout and features.

\section{Electronic Text}

The electronic text was created specifically for this study and contained narrative identical to that found in the student's textbook. However, it was necessary for participants to click on the green links embedded in the Power Point to retrieve additional information including photographs of war leaders, the diary entry, the cause-effect chart, and definitions for vocabulary words. After clicking on these links and viewing the information, students were directed to click on a link that said "Go Back" that returned them to the narrative. Several of the questions on the constructed response assessment tested knowledge of information contained within these links. This allowed me to gauge if students were using the links, which is a critical aspect of electronic text reading. At the onset of the study, I modeled (on the Smart Board) how to use the embedded links and “Go Back" features to ensure that students were comfortable with how to retrieve additional information and then return to the narrative.

\section{Instruments}

\section{Prior Knowledge Assessment}

Before the participants were asked to read the assigned text, they completed a written prior knowledge assessment in an effort to determine familiarity with the topic of World War II. 
Five questions were posed, and each was scored on a 0-2 scale. Responses were scored as correct (2), partially correct (1), or incorrect (0). Using a procedure similar to that used by Leslie and Caldwell (2004), scores for each question were summed to provide one final score for total prior knowledge, which was then converted to a percentage (see Appendix A).

\section{Unaided Retell}

The first instrument that was used to assess comprehension was an unaided retell, which required the participants to retell what they had just read, in paragraph form. Students were prompted to write an extended constructed response (ECR) that contained main idea statements with supporting details. They were not permitted to reference the text when writing this ECR. A retelling scoring sheet was created that listed main concepts from the text, as well as specific details, similar to that of Leslie and Caldwell's Qualitative Reading Inventory-4 (2006). The number of main ideas and supporting details written in the students’ paragraphs were compared to the retelling scoring sheet and then tallied to determine the number of details that students recalled during the retell (see Appendices B and C).

Constructed- response Assessment

The second instrument for assessing comprehension was a constructed response assessment containing traditional questioning that varied from lower-level thinking, such as basic recall questions, to higher-level thinking questions, which required participants to analyze and evaluate sections of the assigned text. See Appendix D. All recall questions were worth 1 point each, based on correctness. The higher-level thinking questions that required a brief-constructed response (BCR) were scored using a 0-1-2-3 writing rubric that is used in all Western County schools (see Appendix E). The assessment was worth a total of 13 points, with raw scores converted to percentages. The students completed this assessment immediately following the 
retell. In contrast to the retell, however, students were able to access the text when constructing their responses. To ensure inter-rater reliability, each BCR was independently scored by another teacher and me, with an agreement rate of 89\%. Disagreements in scoring were resolved through a discussion with a third teacher in which consensus was reached.

\section{Student Survey}

This instrument, generated specifically for this study, was intended to gather information in regard to students’ perceptions of reading print and electronic text, as well as to gain an understanding of the behaviors exhibited by the students while reading. On the initial part of this written survey, students were asked to agree or disagree with a list of seven statements dealing with their feelings about reading print and electronic text. On the second part of the survey, students read a list of strategies and were instructed to place a check mark next to those that were utilized during their reading for this particular study. Through this task, it could be determined if students were using the same strategies with both formats of text or if some strategies were used more frequently with a certain medium of text. I elected to orally read the survey to the participants, requesting they follow along with me, to ensure that participants fully understood each statement on the survey. They were encouraged to ask questions to seek clarification, if necessary. In an effort to gain a true depiction of the participants’ perceptions, I often paraphrased and elaborated on the statements in the survey. I encouraged participants to respond in an honest manner, as opposed to reporting what they believed would please their teachers or me (see Appendix F).

\section{Data Collection}

Data collection took place at Western Middle School, over a two- week period, in May and June of 2009, subsequent to receiving approval from the Institutional Review Board (IRB). 
All data were collected during the 78- minute language arts block, with data collected from one classroom at a time, so that I could be present to ensure that the testing conditions remained consistent. The site chosen was my classroom, which houses 15 computers.

\section{Procedure}

Following an explanation of my research purpose and agenda, participants were assigned an identification number. Each participant then completed a short prior knowledge task to determine familiarity with the topic of World War II. Participants were then randomly assigned to read text in either print or electronic format. Upon completion of the reading, each student constructed a written, unaided retell in which they identified the main ideas and supporting details from the text, in paragraph form. When constructing this paragraph, participants were not permitted to access the text. Next they completed the constructed- response assessment and were permitted to access the text for assistance on this task. Finally, participants were asked to complete a survey regarding their perceptions of reading various formats of text, as well as their reading behaviors. Chapter 4 will provide the results of the comprehension assessment measures and findings from the student survey. 


\section{CHAPTER IV}

\section{RESULTS}

This investigation explored relationships between format of text (electronic or printbased) and reading comprehension of adolescent readers. Also in question were potential influences on comprehension from related measures including academic placement of participants, gender, prior knowledge of the content, and overall reading ability. Participants' reading preferences and self-reported reading behaviors were also considered, as the following questions guided this research:

1) What is the relationship between the format of the text and comprehension, as measured by an unaided text retell and constructed- response assessment?

2) What is the relationship between each of academic placement, gender, prior knowledge, and overall reading ability with format of text and any effects on unaided text retell and constructed-response assessment?

3) Which format of text is more highly preferred by seventh grade students?

4) What strategies do seventh grade students report using when reading print and electronic text?

Findings revealed that neither form of text delivery offered an advantage to readers on either the unaided text recall or the traditional questioning on the constructed-response assessment. Additionally, no interactions between text format and the accompanying covariables offered advantages to the readers. Academic placement and overall reading ability were related to both text comprehension measures, with advantages favoring higher academic placement groups. Gender also offered advantages, with females predicted to have higher scores on the constructed-response assessment but not on retell measures. Having prior knowledge of 
the subject matter was advantageous for participants’ retell measures but not on the constructedresponse assessment. The intricacies of the analyses follow, beginning with findings from the unaided text retell, followed by findings of the constructed-response assessment.

\section{Influences on Unaided Written Retell of Text}

After reading the assigned text, electronically or text-based, participants attempted to write retells of what they could recall about World War II (See Appendix B). The task took place without text availability for look backs. Details from the written retells were tallied on a retell score sheet (see Appendix C) in a manner similar to that of Leslie and Caldwell's Qualitative Reading Inventory-4 (2006).

Multiple regression served to measure the relationships between the independent variable (format of text) and four potential co-variables (academic placement level, gender, prior knowledge, and overall reading ability) on the unaided retell (the dependent variable). Tools in SPSS, version 17 (2009) utilized univariate general linear models to calculate a series of regression equations for the variables.

\section{Relationships of Text Type and Unaided Retell of Text}

Participants in this study were randomly assigned to read either print or electronic text in an effort to determine which format, if either, led to higher levels of comprehension. Regression analysis indicated that format of the text was not a significant predictor of comprehension, as measured by the retell assessment $\mathrm{F}(1,126)=.15, \mathrm{p}<.05 . \mathrm{R}^{2}$ for the model was .001 , indicating that less than $1 \%$ of the variance could be accounted for by the format of the text. The mean score for participants reading conventionally printed text was $10.08(\mathrm{SD}=8.39)$ as compared to a mean of 10.52 (SD = 5.9) for electronic text. Additional follow-up analyses were conducted to test for any interaction effects. There were no two-way interactions between text type and 
gender, text type and academic level, text type and prior knowledge, or text type and overall reading ability. In essence, it did not matter if participants read print or electronic text, as comprehension was not influenced by text format. Comprehension was, however, influenced by other variables. The next section presents additional findings concerning each of these variables, beginning with academic placement level of the participants.

Relationships of Academic Placement Level and Unaided Retell of Text

Students at Western Middle School were previously grouped homogeneously according to academic ability and achievement. Placement levels include honors, merit, general, and special education. Placements were determined prior to the 2008-2009 school year and were based upon Maryland School Assessment scores, Gates-MacGinitie Reading Test scores, and teacher recommendations.

In the present study, there were no statistical interactions between academic placement level and text type. Results did indicate a main effect for academic placement, however. This variable accounted for $29 \%$ of the variance in retell measures and was a significant fit of data $\mathrm{F}(1,126)=51.33, \mathrm{p}<.05$. Descriptive statistics are presented in the following table.

Table 1

Descriptive Statistics for the Unaided Retell Based Upon Academic Level and Format of Text

\begin{tabular}{|l|l|c|c|}
\hline $\begin{array}{l}\text { Academic Placement } \\
\text { of Students }\end{array}$ & Format of Text & Mean & Standard Deviation \\
\hline Honors & Print & 17.33 & 10.21 \\
& Electronic & 17.00 & 5.28 \\
\hline Merit & Print & 7.76 & 5.05 \\
& Electronic & 8.83 & 4.77 \\
\hline General & Print & 4.55 & 2.81 \\
& Electronic & 8.47 & 4.02 \\
\hline Special Education & Print & 5.80 & 2.17 \\
& Electronic & 2.50 & .71 \\
\hline
\end{tabular}


As evidenced in Table 1, participants in higher placement levels earned higher retell scores, regardless of text type. However, there were inconsistencies in scores for general and special education students. General level students were able to recall more details after reading electronic text, whereas special education students benefitted from reading conventionally printed text. Although noteworthy, this inconsistency was not significant enough to create an interaction effect between format of text and academic placement level.

Relationships of Gender and Unaided Retell of Text

There were also no statistical interactions between gender and text type, as measured by the unaided retell $\mathrm{F}(1,126)=1.97, \mathrm{p}<.05 . \mathrm{R}^{2}$ for the model was .015 , indicating a variance of only $2 \%$. Additionally, differences in mean scores as an effect of gender were not significant. Males in the study had a mean score of 11.39 (SD =9.0) on retell measures, while the mean score for females was 9.51 (SD = 5.6). There was little discrepancy in gender among participants reading electronic text, with males earning a mean score of $10.63(\mathrm{SD}=6.37)$ and females earning a mean score being $10.52(\mathrm{SD}=5.65)$. There was a more noticeable inconsistency in mean scores with print text, as mean score for males was $12.42(\mathrm{SD}=11.62)$ and females was $8.85(\mathrm{SD}=5.58)$

Relationships of Prior Knowledge and Unaided Retell of Text

At the onset of the study, previous to reading the assigned text and constructing the retell, participants completed a short prior knowledge task on the topic of World War II (See Appendix A). Results indicated no significant interactions between prior knowledge and text type on the dependent variable of retell. A main effect for prior knowledge, though, indicated that participants with higher levels of prior knowledge also had higher retell results. The model 
accounted for $28 \%$ of the variance in comprehension scores and was a significant fit of data $\mathrm{F}$ (1, $125)=48.58, \mathrm{p}<.05$

\section{Relationships of Overall Reading Ability and Unaided Retell of Text}

In early June, just a few weeks after data collection for this study concluded, all seventh grade students in Western Middle School completed assessments on the Gates- MacGinitie Reading Test, a standardized, two-part test measuring vocabulary and passage comprehension. The comprehension subtest score served as a measure of overall reading ability for the present study.

Results from the regression analysis indicated a benefit for overall reading ability, as students with higher scores on the Gates- MacGinitie assessment also performed at higher levels on the text retell. This model accounted for 33\% of the variance in retell scores and was a significant fit of data $\mathrm{F}(1,126)=60.62, \mathrm{p}<.05$.

\section{Model Summary}

To sum up, the overall model summary for retell measures was significant $F(5,121)=$ 25.39, $\mathrm{p}<.05 . \mathrm{R}^{2}=.512$, which indicated that prior knowledge, academic placement, and overall reading ability accounted for $51 \%$ of the variance in retell scores. Therefore, other related reader variables accounted for the remaining $49 \%$ of influence on retell measures.

\section{Constructed-response Assessment}

After the participants composed details of what they recalled about World War II in an unaided retell, they responded to traditional, open-ended questions on the constructed-response assessment (See Appendix D). This measure consisted of eight questions, six of which were basic recall, with two higher level questions requiring participants to compose a briefconstructed response (BCR). Unlike the retell assessment, participants were able to reference the 
text on this assessment. Basic recall questions were worth one point each, based on correctness, while the brief-constructed responses that incorporated higher-level thinking skills were scored using a 0-3 rubric. Scores for each question were summed to provide one final score for total comprehension (out of a possible 13 points), which was then converted and reported as a percentage.

As with the first dependent variable, regression analysis served to measure the influences of the predictor variable (format of text) and four potential co-variables (academic placement level, gender, prior knowledge, and overall reading ability) on the constructed-response assessment. Tools in SPSS, version 17 (2009) utilized univariate general linear models to calculate a series of regression equations for the variables.

Relationships of Text Type and Constructed-response Assessment

Resembling the findings of the unaided text retell, text type was not a significant predictor of comprehension as measured through traditional questioning on the constructedresponse assessment $\mathrm{F}(1,124)=.034, \mathrm{p}<.05$. The mean score for print text was $71.03(\mathrm{SD}=$ 18.47) as compared to a mean of $71.50(\mathrm{SD}=18.27)$ for electronic text. Additionally, there were no two-way interactions between text type and gender, text type and academic level, text type and prior knowledge, or text type and reading ability. The results now turn to related questions for each of the co-variables, beginning with academic placement level of the participants. Relationships of Academic Placement Level and Constructed-response Assessment

There were no statistical interactions between academic placement level and format of text. However, results did indicate a main effect for academic placement $F(1,124)=46.02$, $\mathrm{p}<.05 . \mathrm{R}^{2}=.271$, signaling that $27 \%$ of the variance in comprehension scores was accounted for by academic placement level. Similar to the retell assessment, honors students were once again 
advantaged, and the largest inconsistency in scores was found with general level participants who performed at higher levels when reading electronic text. Means and standard deviations are displayed in the following table.

Table 2

Descriptive Statistics for the Constructed-response Assessment Based upon Academic Level and Format of Text

\begin{tabular}{|l|l|l|l|}
\hline $\begin{array}{l}\text { Academic Placement } \\
\text { of Students }\end{array}$ & Format of Text & Mean & Standard Deviation \\
\hline Honors & Print & 83.62 & 13.45 \\
& Electronic & 83.47 & 10.39 \\
\hline Merit & Print & 71.90 & 14.22 \\
& Electronic & 67.96 & 17.02 \\
\hline General & Print & 55.91 & 15.48 \\
& Electronic & 69.58 & 20.47 \\
\hline Special Education & Print & 44.60 & 15.02 \\
& Electronic & 42.00 & 5.66 \\
\hline
\end{tabular}

Relationships of Gender and Constructed-response Assessment

Similar to the findings on retell measures, there was not a statistically significant interaction between text format and gender, as measured by the constructed-response assessment. Unlike the findings on the retell assessment, however, differences in mean scores as an effect of gender were significant on this assessment measure $F(1,124)=6.07, \mathrm{p}<.05$. The model accounted for $5 \%$ of the variance in comprehension scores. Females outperformed their male counterparts, regardless of text type. For print text, males earned a mean score of 65.38 (SD = 17.77), while females’ mean score was $74.34(\mathrm{SD}=18.27)$. For electronic text, males had a mean score of $68.19(\mathrm{SD}=17.70)$ on traditional questioning, and females' mean score was 75.52 $(\mathrm{SD}=18.82)$ 


\section{Relationships of Prior Knowledge and Constructed-response Assessment}

Results indicated no statistically significant interactions between prior knowledge and text type. Having prior knowledge of the subject content was not an advantage for participants on the constructed-response assessment, which is in contrast to the findings of the unaided retell. The model accounted for only 3\% of the variance in comprehension scores and was not a significant fit of data $\mathrm{F}(1,123)=4.35, \mathrm{p}<.05$.

\section{Relationships of Overall Reading Ability and Constructed-response Assessment}

Although there was not found to be a statistical interaction between format of text and overall reading ability, results from the regression analysis indicated a benefit for reading ability, as students with higher scores on the Gates- MacGinitie assessment also performed at higher levels on the constructed-response assessment. The model accounted for $17 \%$ of the variance and was a significant fit of data $F(1,124)=25.50, \mathrm{p}<.05$.

\section{Model Summary}

The overall model summary for the constructed-response assessment was significant $\mathrm{F}(5,119)=11.40, \mathrm{p}<.05 . \mathrm{R}^{2}=.324$, which indicated that academic placement, gender, and overall reading ability accounted for $33 \%$ of the variance in scores on this assessment. Consequently, a much larger proportion (67\%) of the influence was due to other related reader variables, aside from academic placement level, gender, and overall reading ability.

Summary of Quantitative Results for the Retell and Constructed-response Tasks Format of the text was not a significant predictor of reading comprehension, despite participants' self-reported preference to reading electronic text. Conversely, participants’ academic placements and overall reading abilities, as measured by the Gates- MacGinitie Reading Test, were significant predictors of comprehension, for both retell and constructed- 
response assessments. Having prior knowledge of the subject content was advantageous for participants on retell measures but did not appear to significantly impact performance on the constructed response assessment. Gender, however, significantly predicted comprehension on the constructed -response assessment but not on retell measures. There were no significant two-way interactions between the format of the text and academic placement, gender, prior knowledge, or overall reading ability. Findings from the student survey will next be presented, offering greater insight into the findings of the preceding regression analyses.

\section{Student Survey Findings- Reading Behaviors}

Following the completion of the two comprehension measures, participants completed a two-part written survey, which was read aloud to them by the researcher, concerning their reading preferences, behaviors, and strategies utilized while reading the assigned text (See Appendix G). In Part 1 of the survey, participants were instructed to respond to a series of statements by circling agree, disagree, or no preference. On the second portion of the survey, participants were instructed to place a checkmark in front of the statements to indicate the reading strategies used during participation in the study. A total of 127 participants completed the Student Survey. Results of the study are presented using descriptive statistics.

\section{Type of Text Preferred}

Statement 1on the student survey read I like the type of text I was assigned to read. Statement 2 read I would have preferred reading the other type of text. Overall, seventh grade students in this study reported a preference to reading electronic text, as compared to conventionally printed text. Fifty-seven percent $(n=33)$ of the 58 participants that read electronic text reported liking this format of text, with an additional $40 \%$ of these participants ( $n$ $=23$ ) claiming no preference to text type. Therefore, $97 \%$ of those reading electronic text were 
satisfied doing so. Only 20\% $(n=13)$ of the 65 participants that read print text reported satisfaction from reading this format of text, with an additional 48\% ( $n=31)$ declaring no preference. Because Statements 1 and 2 were attempting to glean the same type of information, the four participants that did not respond in a manner that proved congruent were eliminated from the preceding results.

\section{Reading Behaviors Outside of School}

Most of my reading done outside of school is electronic text. Roughly half (52\%) of the 127 participants agreed with this statement. There was little discrepancy in gender, as 53\% of the males and 51\% of the females reported agreement. When data was further disaggregated by academic level, the participants claiming to read predominantly electronic text outside of the school setting was special education (86\%), followed by the general level students (65\%), and then merit level students (57\%). Only 26\% of the honors students reported reading chiefly electronic text outside of the school.

Students were further prompted to name something they had recently read in electronic format. The most frequent responses included the following:

- the reading of emails (36)

- text messages (18)

- $\quad$ My Space bulletins (13)

- $\quad$ science research for an upcoming project (11)

- $\quad$ sporting events (8)

- weather (7)

- online shopping (3)

- off-road vehicles (3) 
- Wikipedia (1)

- $\operatorname{blogs}(1)$

- news articles (1)

- hunting tips (1)

- Thirteen students reported not reading anything online while not in school.

Preference for Electronic Textbooks

If our school was voting to keep our current textbooks or purchase electronic textbooks, I would choose the electronic textbooks. An overwhelming $83 \%$ of participants were in favor of purchasing electronic textbooks, with an additional 13\% claiming no preference. Seventy-eight percent of the males and $87 \%$ of the females would choose to purchase electronic texts if given the option. Merit students most highly supported the purchase of these texts (91\%), closely followed by general level students (87\%) and then special education students (86\%). Sixty-three percent of the honors students were in favor of using this format of textbook, as opposed to the traditional textbooks currently in use.

Time Spent Reading Electronic Text

I spend 3 or more hours reading electronic text each week. Fifty-seven percent of the participants agreed with this statement. Sixty-four percent of the females reported spending an excess of three hours reading electronic text each week, while $48 \%$ of males agreed with this statement. Higher percentages of merit and general level students reported spending 3 or more hours reading electronic text on a weekly basis ( $67 \%$ and $61 \%$, respectively). Forty-six percent of honors students supported this statement, with a lower percentage (29\%) of special education students reading electronic text more than 3 hours weekly. 


\section{Behaviors Exhibited When Reading Electronic Text}

Most of my electronic text reading is browsing or sampling text, as opposed to reading text. This statement was supported by $84 \%$ of the participants in this study, with $76 \%$ of the males and $90 \%$ of the females agreeing. High percentages of agreement were reported from the honors (86\%), merit (85\%), and general level students (84\%). Conversely, only 57\% of the special education participants concurred that most of their time spent on computers was either browsing or sampling text.

\section{Comprehension of Electronic Text}

The last statement on part 1 of the student survey read I believe that I comprehend electronic text better. Sixty-three percent of the participants agreed with this statement. Eleven percent claimed they do not believe that there is a difference in their comprehension based upon the format of the text. Thirty-eight percent of the males and $42 \%$ of the females claimed to better comprehend electronic text. In reference to academic level, the special education students reported an $86 \%$ agreement rate. Seventy-four percent of merit level students and 65\% of general level students reported increased comprehension with electronic text, while fewer honors students made the same claim (40\%).

\section{Preference of Text Type}

Seventh grade students in this study prefer reading electronic text, as evidenced by the findings of statements 1, 2, and 4 on part 1 of the student survey. From statements 1 and 2, it was revealed that $57 \%$ of the participants that read electronic text were satisfied doing so, with an additional $40 \%$ claiming no preference between the two text types. Only $20 \%$ of the participants that read print text reported satisfaction with this format of text, with an additional $48 \%$ declaring no preference. Findings from statement 4 on the survey further supported the assertion that 
students prefer reading electronic text, as $83 \%$ of participants were in favor of adopting electronic textbooks in place of conventional textbooks, with an additional $13 \%$ claiming no preference.

\section{Summary of Student Survey Findings- Reading Behaviors}

The purpose of the second portion of the student survey was to gain insight in regards to strategy use. Specifically, it seemed imperative to investigate if the same strategies were used with both print and electronic texts. It was also important to ascertain if males and females reported utilizing similar strategies and if participants placed in different academic levels claimed to use distinctive strategies. A narrative summary, accompanied by related tables, follows.

\section{Making Predictions}

When reading informational text, students at Western Middle School are routinely encouraged to use the titles and subtitles to predict the type of information they will likely read in each section of text. This data is summarized in Table 3.

Table 3

Number and Percentage of Participants Making Predictions While Reading

\begin{tabular}{lcc}
\hline & Number of Participants & Percentage \\
\hline Total using this strategy & & $24 \%$ \\
Print & 30 & $25 \%$ \\
Electronic & 17 & $22 \%$ \\
Males & 13 & $26 \%$ \\
Females & 15 & $22 \%$ \\
Honors & 15 & $19 \%$ \\
Merit & 7 & $20 \%$ \\
General & 11 & $33 \%$ \\
Sped & 10 & $29 \%$
\end{tabular}


In the present study, a slightly higher percentage of participants who read print text (25\%) claimed to make predictions while reading the assigned text. Males (26\%) reported using this strategy more often than females (22\%), and a greater number of general (33\%) and special education students (29\%) used this strategy as compared to students in honors (19\%) and merit placements (20\%).

\section{Self-monitoring}

Participants who read electronic text reported self-monitoring their comprehension more often (62\%) than those who read conventionally printed text (46\%). Males and females reported using this strategy comparably (54\% and 53\%, respectively). Honors (61\%) and merit level students (63\%) used the strategy most often, with general level students (30\%) self-monitoring the least of the four academic levels (see Table 4).

Table 4

Number and Percentage of Participants Who Self-monitored Comprehension While Reading

\section{Number of participants}

Total

Print

Electronic

Males

Females

Honors

Merit

General

Sped

68

31

37

31

37

22

34

9
Percentage

$54 \%$

$46 \%$

$62 \%$

$53 \%$

$54 \%$

$61 \%$

$63 \%$

$30 \%$

$43 \%$

\section{Connecting to Prior Knowledge}

By a narrow margin, participants who read electronic text (80\%) reported making more connections to their prior knowledge than students reading conventional print text (76\%). A greater number of males (83\%) reported connecting to their prior knowledge as compared to 
their female counterparts (74\%). Honors students most often reported using this strategy (81\%), closely followed by merit level students (80\%). A high proportion of general (73\%) and special education students (71\%) also reported connecting to prior knowledge while reading the assigned text, as shown in the following table.

Table 5

Number and Percentage of Participants Who Connected to Prior Knowledge While Reading

\begin{tabular}{lcc}
\hline & Number of Participants & Percentage \\
\hline Total & & $78 \%$ \\
Print & 99 & $76 \%$ \\
Electronic & 51 & $80 \%$ \\
Males & 48 & $83 \%$ \\
Females & 48 & $74 \%$ \\
Honors & 51 & $81 \%$ \\
Merit & 29 & $80 \%$ \\
General & 43 & $73 \%$ \\
Sped & 22 & $71 \%$
\end{tabular}

Using the WIN Strategy to Identify Main Ideas

Students at Western Middle School are encouraged to use the WIN strategy to assist them in identifying the main idea of passages found in informational text. The W in the WIN acronym stands for who or what is the reading about? The I represents important facts or details, and the $\mathrm{N}$ stands for number of words (Students are encouraged to write the main idea in as few number of words as possible). The strategy is routinely modeled in all general and special education classrooms, with less use in the upper academic level classrooms.

Males (16\%) and electronic text readers (13\%) reported using this strategy most often, as well as general (23\%) and special education students (43\%). Very few students in the honors (8\%) or merit placements (2\%) utilized the WIN strategy.

Table 6 follows on the next page. 
Number and Percentage of Participants Who Utilized the WIN Strategy

\begin{tabular}{lcr}
\hline & Number of Participants & Percentage \\
\hline Total & & $11 \%$ \\
Print & 14 & $9 \%$ \\
Electronic & 6 & $13 \%$ \\
Males & 8 & $16 \%$ \\
Females & 9 & $7 \%$ \\
Honors & 5 & $8 \%$ \\
Merit & 3 & $2 \%$ \\
General & 1 & $23 \%$ \\
Sped & 7 & $43 \%$
\end{tabular}

\section{Summarizing at the End of Each Section}

When reading informational text, students at Western Middle School are encouraged to summarize at the end of each section of text before proceeding to the next section. A much higher percentage of participants who read electronic text (30\%) reported doing so. As compared to their female counterparts (16\%), a larger number of males (24\%) made the same claim. The percentage of participants in the honors (19\%), merit (19\%) and special education (23\%) was fairly consistent, with a higher percentage of general level students (23\%) summarizing at the end of each section of text (see Table 7).

Table 7

Number and Percentage of Participants Who Summarized at the End of Each Section of Text

Number of Participants

\begin{tabular}{lrc}
\hline Total & 25 & $20 \%$ \\
Print & 7 & $10 \%$ \\
Electronic & 18 & $30 \%$ \\
Males & 14 & $24 \%$ \\
Females & 11 & $16 \%$ \\
Honors & 7 & $19 \%$ \\
Merit & 10 & $19 \%$ \\
General & 7 & $23 \%$ \\
Sped & 1 & $14 \%$
\end{tabular}




\section{Using the CPR Strategy to Identify the Meaning of Unknown Words}

The CPR strategy is used to identify the meaning of unknown words. The C in this acronym stands for context clues, the P represents parts of words, and the R stands for resource books. Students placed in the Voyager reading intervention program, which includes all general and special students in Western Middle School, practice this strategy routinely, as it is a central part of the scripted program. The strategy is modeled less often in upper academic level classrooms.

Participants reading electronic text (18\%) reported using this strategy more often than those reading print text (12\%). There was little discrepancy in gender, with $16 \%$ of males and $14 \%$ of females reportedly using this strategy. General level students (40\%) reported using the strategy most often, followed by special education students (14\%), while fewer honors (11\%) and merit level students (3\%) reported using the CPR strategy (see Table 8).

Table 8

Number and Percentage of Participants Who Utilized the CPR Strategy

\begin{tabular}{lrc}
\hline & Number of Participants & Percentage \\
\hline Total & & $15 \%$ \\
Print & 19 & $12 \%$ \\
Electronic & 8 & $18 \%$ \\
Males & 11 & $16 \%$ \\
Females & 9 & $14 \%$ \\
Honors & 10 & $11 \%$ \\
Merit & 4 & $3 \%$ \\
General & 2 & $40 \%$ \\
Sped & 12 & $14 \%$
\end{tabular}

\section{Using Text Features}

A school-wide focus at Western Middle School is encouraging students to utilize text features in an effort to increase comprehension of informational text. A higher percentage of 
males (91\%) and participants reading print text (94\%) reported using text features. One hundred percent of the special education students used this strategy, with a high percentage of general (97\%) and merit level students (93\%) doing the same (see Table 9).

Table 9

Number and Percentage of Participants Who Utilized Text Features to Increase Comprehension

\begin{tabular}{lcc}
\hline & Number of Participants & Percentage \\
\hline & & \\
Total & 114 & $90 \%$ \\
Print & 63 & $94 \%$ \\
Electronic & 51 & $85 \%$ \\
Males & 53 & $91 \%$ \\
Females & 61 & $88 \%$ \\
Honors & 28 & $78 \%$ \\
Merit & 50 & $93 \%$ \\
General & 29 & $97 \%$ \\
Sped & 7 & $100 \%$
\end{tabular}

Reading the Summary of the End of the Lesson

Table 10

Number and Percentage of Participants Who Read the Summary at the End of the Lesson

\begin{tabular}{lcc}
\hline & Number of Participants & Percentage \\
\hline Total & 72 & $57 \%$ \\
Print & 33 & $49 \%$ \\
Electronic & 39 & $65 \%$ \\
Males & 33 & $57 \%$ \\
Females & 39 & $57 \%$ \\
Honors & 23 & $64 \%$ \\
Merit & 30 & $56 \%$ \\
General & 14 & $47 \%$ \\
Sped & 5 & $71 \%$
\end{tabular}


Participants who read electronic text (65\%) more often reported reading the summary at the end of the lesson, as compared to those reading print text (49\%). There was no discernable difference in gender (57\% for both males and females). Special education students (71\%) reportedly read the summary most often, followed by the honors students (64\%), merit students (56\%), and then general level students (47\%). Please refer to the preceding table for additional descriptive statistics.

\section{Summary of Results from Part 2 of the Student Survey- Strategies Format of Text}

Participants who read electronic text used a greater number of strategies than those reading conventionally printed text. A higher percentage of these participants self-monitored while reading, connected to their prior knowledge, used the WIN strategy to identify main ideas, summarized at the end of each section of text, used the CPR strategy to identify the meaning of unknown words, and read the summary at the end of the chapter. Participants reading print text more frequently made predictions while reading and used text features to a greater extent than those reading electronic text.

\section{Gender}

Males utilized a greater number of strategies than females in this study. A higher percentage of males made predictions while reading, connected to their prior knowledge, used the WIN strategy, summarized at the end of each section of text, utilized the CPR strategy, and used text features. An equal percentage of male and females read the summary at the end of the chapter. Females self-monitored more often than males by 1 percent. 


\section{Academic Placement}

A higher percentage of special education students reported reading the summary at the end of the chapter, as well as utilizing the WIN strategy and using text features. A greater percentage of general level students made predictions while reading, summarized at the end of each section of text, and used the CPR strategy. Merit level students self-monitored most often, and honors students connected to their prior knowledge to a greater extent than their peers.

\section{Chapter Summary}

A series of regression analyses measured the relationships between the format of text and two comprehension assessments. The relationships of other influences on comprehension were also considered including academic placement of participants, gender, prior knowledge of the content, and overall reading ability. Table 11 provides a summary of these findings.

Table 11

Summary of Quantitative Findings from the Regression Analyses

\begin{tabular}{|l|l|l|}
\hline & Retell & Constructed-response \\
\hline Format of Text & Not significant & Not significant \\
\hline Academic Placement Level & Significant & Significant \\
\hline Gender & Not significant & Significant \\
\hline Prior Knowledge & Significant & Not significant \\
\hline Overall Reading Ability & Significant & Significant \\
\hline
\end{tabular}

Findings revealed that the format of the text was not a significant predictor of comprehension, whereas participants' academic placements and overall reading abilities were significant predictors of comprehension, for both retell and constructed-response assessments. 
Having prior knowledge of the subject content was advantageous for participants on retell measures but did not appear to significantly impact performance on the constructed response assessment. Conversely, gender significantly predicted comprehension on the constructed response assessment but not on retell measures. There were no significant two-way interactions between the format of the text and academic placement, gender, prior knowledge, or overall reading ability.

Results from a two-part student survey were next summarized, which revealed that participants in this study preferred reading electronic text and utilized a wide array of comprehension strategies, which are summarized in Table 12.

Table 12

Summary of Strategy Use

\begin{tabular}{|l|l|l|l|}
\hline Strategy & $\begin{array}{l}\text { Format of Text in } \\
\text { Which Strategy Was } \\
\text { Used Most Often }\end{array}$ & $\begin{array}{l}\text { Gender Using the } \\
\text { Strategy Most Often }\end{array}$ & $\begin{array}{l}\text { Academic Placement } \\
\text { Level in Which } \\
\text { Strategy Was Used } \\
\text { Most Often }\end{array}$ \\
\hline Made Predictions & Print & Males & General \\
\hline Self-monitored & Electronic & Females & Merit \\
\hline $\begin{array}{l}\text { Connected to Prior } \\
\text { Knowledge }\end{array}$ & Electronic & Males & Honors \\
\hline $\begin{array}{l}\text { Used the WIN } \\
\text { Strategy for Main } \\
\text { Ideas }\end{array}$ & Electronic & Males & Special Education \\
\hline $\begin{array}{l}\text { Summarized at the } \\
\text { end of each section }\end{array}$ & Electronic & Males & General \\
\hline $\begin{array}{l}\text { Used the CPR } \\
\text { Strategy }\end{array}$ & Electronic & Males & General \\
\hline Used Text Features & Print & Males & Special Education \\
\hline $\begin{array}{l}\text { Read the summary at } \\
\text { the end of the lesson }\end{array}$ & Electronic & Same & Special Education \\
\hline
\end{tabular}


The following chapter presents a detailed discussion of these findings and reviews implications for classroom practice and future research. Limitations of the study will also be discussed. 


\section{CHAPTER V}

\section{DISCUSSION}

The primary purpose of this study was to determine if the format of the text influenced performance on reading comprehension tasks by seventh grade students. The study also explored how additional co-variables, including prior knowledge of the subject matter, gender, academic placement of the participants, and overall reading ability might influence comprehension, either through interactions with text format or as main effects. Participants also had opportunities to identify individual perceptions of text format preferences, as well as specific reading strategies utilized during the respective comprehension tasks. Findings from across data sources have led to several conclusions.

\section{Conclusions}

\section{Conclusion 1: Format of Text Does Not Predict Comprehension}

Findings from the regression analyses revealed that text type was not a significant predictor of reading comprehension, despite participants' self-reported preference to reading electronic text. If self-reported preference was accurate, one might have expected increased comprehension when reading electronic text, as was found to be the case with previous studies conducted by Fry (2007); Alvarez (2006); Joly, Capovilla, Bighetti, and Nicolau (2005); Joly and Lomonaco (2003); and Reinking (1993). According to Pitcher, et al. (2007), “Using adolescents’ preferred reading materials and modes of instruction will lead to increased motivation, and perhaps to improvements in reading outcomes” (p. 378). And perhaps not, the present findings suggest, as participants in this study performed in a comparable manner, regardless of text type. 
Although the conjectures of Pitcher et al. are consistent with classroom expectations, others have presented contradictory results. For example, Dungworth, McKnight, and Morris (2008), Standish (1992), Casteel (1988-1989), Helfeldt and Henk (1985), and Manzo (1985) reported that there were no statistically significant differences in reading comprehension between the two formats of text. Although the present study built upon ideas from the aforementioned studies, the present study was somewhat unique in that it did not include narration with the text, nor were electronic dictionaries or other scaffolds available to participants. Regardless of the absence of these scaffolds, there was no significant difference in comprehension across formats of text.

Many classroom teachers would expect readers to perform at higher levels on comprehension assessments following the reading of conventionally-printed text. Teachers at Western Middle School expected the same, as most of the day-to-day teaching is based upon explicit comprehension instruction using a variety of traditionally printed materials. Students in the honors and merit tracks have virtually no explicit instruction in the reading of electronic text. General and special education students have weekly instruction and interaction with electronic text in classrooms making use of the Voyager curriculum; however, their interaction with electronic text in content area classes is quite limited, as the content teachers rely heavily on textbooks and other print-based materials.

Because of students' interest in reading electronic text, along with the vast amount of time students spend on the Internet outside of the school setting, they are obviously developing the necessary comprehension skills and strategies incidentally. Through trial and error, they are learning how to read and comprehend electronic text without explicit instruction or modeling from teachers. Furthermore, proficient readers tend to have the ability to transfer their print text 
reading strategies to the computer environment. According to Duke, Schmar-Dobler, and Zhang (2006), skilled hypertext readers utilize a number of comprehension strategies which include setting a purpose for reading, activating prior knowledge, previewing, predicting, attending to text structure and main idea, evaluating the text and text information, and monitoring. These are some of the same strategies that skilled readers use when reading conventionally printed text, allowing for a smooth transfer of strategies to the electronic environment. Results from the present study indicate that despite strategies utilized in either environment, participants performed in a comparable manner regardless of the format of text.

\section{Conclusion 2: Multiple Variables Impact Comprehension}

Although format of the text did not impact comprehension measures, other variables did indeed influence comprehension, and in some cases, confirms what those in the field already know about literacy instruction and best practices. The present study reaffirms that having prior knowledge is advantageous for readers. Participants with increased prior knowledge tend to better facilitate comprehension, which proved to be true in the present study with retell measures. The present study also confirms what numerous gender and literacy studies have shown in reference to reading performance for males and females. Adolescent female readers tend to outperform their male counterparts on standardized comprehension measures. These variables, as well as the academic placement of the participants, will next be discussed.

Academic Placement of the Students

Participants’ academic placements were significant predictors of comprehension, as measured by both the retell and constructed-response assessments. There were advantages to honors students across both tasks. This was to be expected. Many honors and merit level students performed at above-average levels on both assessment measures, regardless of the format of text, 
which is parallel to their performances in the classroom. Although there were no statistical interactions between format of text and academic placement level, there were interesting inconsistencies across the data. For instance, general level participants who read electronic text scored higher than those reading conventionally printed text. The general level students also outperformed the higher level merit students on the constructed-response assessment when reading electronic text. Because the general level students are participants in the Voyager reading intervention program, they read electronic text weekly. The increased exposure to this type of text, which contains many scaffolds and prompts, has undoubtedly prepared them for reading this medium of text more successfully. The electronic reading selections are short, current, and high-interest; therefore, students are more motivated to read this format of text and are subsequently more highly engaged as they take an active role in text construction. Additionally, these same students reported through the student survey that their home literacy reading habits include chiefly electronic text, again leading to increased exposure and experience with this format of text.

Although the special education students demonstrated increased comprehension after reading print text, the number of participants $(n=7)$ was possibly too small to be generalized to the population. However, this finding does support a trend in the intervention classrooms at Western Middle School- special education students still perform at higher levels on the print assessments that follow the reading of printed text, as opposed to the electronic assessments that follow electronic text reading. According to Coiro and Dobler (2007), difficulties experienced by struggling readers are compounded when reading electronic text. They tend to lack prior knowledge and interact more passively with this type of text. This is problematic since electronic text reading is such an active process, often leading to cognitive overload for struggling readers. 
It is important to note that at the time of data collection for this study, students in the seventh grade special education classroom had only been enrolled in this intervention program for five months, as compared to the general level students who had been receiving the intervention for eight months. Perhaps this trend in data for special education students will change once students have spent more time immersed in the Voyager curriculum and have increased interaction and instruction with electronic text. The teacher will also have more familiarity with the program, which could impact these findings as well.

\section{Prior Knowledge}

Much research has been conducted on the correlation between prior knowledge and overall reading comprehension. In the present study, having prior knowledge was an advantage for participants, as evidenced by retell measures. Prior knowledge did not, however, significantly impact performance on the constructed-response assessment. Quite possibly, this difference is a result of participants not being permitted to reference the text when retelling what they had read. Therefore, they had to rely on their memories, as well as their prior knowledge of World War II, to facilitate adequate comprehension. On the constructed-response assessment, having prior knowledge was less critical because participants were allowed to access the text to get assistance with answers. In this instance, having adequate search strategies was most likely more critical than having prior knowledge. Additionally, without having a teacher to activate students’ prior knowledge and create situations to link to and build upon the existing schema, simply having the pre-existing knowledge might not be adequate.

\section{Gender}

Although gender was not a factor with retell ability, it was a main effect with the ability to answer traditional questions on the constructed-response assessment. Females significantly 
outperformed males on this assessment. Because participants were able to access the text when answering these questions, it is possible that females have more refined search strategies. Perhaps they more successfully use the headings and subheadings to assist them in information retrieval, along with the use of the pictures and charts. Another conjecture is that females have more advanced expressive language. According to Slocumb (2004), differences in language acquisition and use of language are two of the most significant differences in males and females. Females in this study generally wrote more detailed brief-constructed responses as compared to their male counterparts, one of which required them to analyze an entry from Anne Frank's diary and the other which asked participants to evaluate the bombing of Japan. It is conceivable that expressive language was a factor that influenced the writing of the brief-constructed responses, as communicating thoughts, feelings, and ideas require hard, precise language (Slocumb, 2007), which can prove more difficult for males.

Interestingly, males reported using a greater variety of strategies than the females. A higher percentage of males reported making predictions while reading, connecting to their prior knowledge, using the WIN strategy to identify main idea, summarizing at the end of each section of text, utilizing the CPR strategy to decipher unknown words, and using text features. Although males made these claims, they did not outperform the females on either assessment. Perhaps additional strategy instruction and modeling is needed, especially for males, who may not be utilizing these strategies properly or to the fullest extent.

\section{Conclusion 3: Strategy Use Varied}

Participants who read electronic text reported using a greater variety of strategies than those reading conventionally printed text. A higher percentage of these participants reported that they self-monitored while reading, connected to their prior knowledge, used the WIN strategy to 
identify main ideas, summarized at the end of each section of text, used the CPR strategy to identify the meaning of unknown words, and read the summary at the end of the chapter. Electronic text reading is undoubtedly a more active process, lending itself to increased strategy use. Students have a new authority with electronic text and are more in control of their learning as they determine their own courses of action when actively reading this type of text (Coiro, 2007).

Participants reading print text more frequently made predictions while reading and reported using text features to a greater extent than those reading electronic text. Most likely this is because the text features in the world history textbook are readily available. They are sizeable, colorful, and difficult to dismiss. With the electronic text, students were required to click on a link to access many of the text features, including a cause-effect chart, photos of the war leaders, and an Anne Frank diary entry. Although participants in this study claimed using the links to these text features, those reading electronic text could easily forego this extra step, thus lessening comprehension.

A higher percentage of special education students reported reading the summary at the end of the chapter, as well as utilizing the WIN strategy and using text features. The last two strategies are routinely modeled in classrooms using the Voyager curriculum where instruction is provided to general and special education students. The classroom teachers model these strategies with print text when progressing through the scripted intervention program. Furthermore, each electronic lesson begins with a reminder about the WIN strategy and then the online reading coach again models the strategy. Text features are also incorporated in each electronic lesson. From these self-reported findings, it seems as if students are beginning to embed these strategies and make use of them when reading independently. 
A greater percentage of general level students reported making predictions while reading, summarizing at the end of each section of text, and using the CPR strategy. Similar to the special education students, these students engage in daily practice with these strategies. Summarizing at the end of each section of the text is synonymous to using the WIN strategy, and as previously stated, each electronic lesson in the Voyager program incorporates this strategy. The CPR strategy is also a staple of the Voyager program and is reinforced and modeled regularly. It appears, through self-reporting measures, that students are using these strategies outside of the intervention classroom as well.

Merit level students in this study reported self-monitoring their comprehension most often. This is a difficult strategy for struggling readers to embed, which is likely a reason why most of the lower level students in the general and special education tracks did not report using this strategy. If strugglers do not understand what they are reading, they often read on instead of employing fix-up strategies. The same is true for those who lack motivation; they simply read ahead without applying metacognitive strategies. Merit level students, most of which do not struggle with reading, claimed to use this strategy while reading the assigned text.

Honors students most often reported connecting to their prior knowledge. These students frequently have more background knowledge and experiences than their lower level peers, often because they tend to read more than their peers. In the present study, the honors students did in fact have greater prior knowledge of World War II than students in lower academic placements, which likely impacted comprehension scores on both the retell and constructed-response assessments. 


\section{Discussion}

\section{Classroom Implications}

By coupling the conclusions of this study with current research, these findings may inspire educators of the $21^{\text {st }}$ century to improve classroom instruction and more successfully meet the needs of our diverse students. Implications for the classroom follow.

First, practitioners must expand the notion of text to include more electronic text reading in every classroom. Ivey (as cited in Pitcher, et al., 2007) asserts that the decline in reading motivation as students progress through middle and high school is the result of a mismatch between reading format and student preferences. "When reading is limited to textbooks and whole-class literature, we limit ourselves as teachers, and our students as readers” (Pitcher et al., 2007, p. 395). The environments of adolescents today are filled with electronic texts, and researchers contend that there needs to be a pedagogical shift so that classroom instruction incorporates these new modes of reading and communication (Walsh, Asha, \& Spraigner, 2007). Since teachers make the most significant contribution to learning, they must be skilled at using electronic media and provide opportunities for reading this format of text.

After expanding the notion to provide greater opportunities for electronic text reading in the classroom, it is important that teachers explicitly model and teach strategies to aid students in comprehending this format of text. Sutherland-Smith suggests that students be taught the chucking technique for synthesizing information from multiple sites, as well as the "snatch and grab” technique to skim for information. Additionally, they must be provided clear search guidelines and limited links, with shortcut lists to sites and search engines. Once on the Web, they must be taught to evaluate the non-textual features of the text, such as images and graphics, and become critical consumers of literacy. Without teaching and modeling these strategies, many 
students, especially struggling readers, will have increased difficulties navigating through and reading electronic text. Again, the ultimate responsibility lies with the teachers who must possess the necessary skills and knowledge to incorporate these strategies.

Teachers must also be acutely aware of students’ personal uses of literacy and what is deemed important to them as readers._Partin and Hendricks (as cited in Pitcher, et al., 2007) suggest that educators broaden their perspectives of what they consider acceptable reading material to include the Internet, popular culture and music, newspapers and magazines, and other options that will invite opportunities for adolescents to become critical consumers of a wide array of texts while reading what they perceive as meaningful in their own lives.

Teachers could incorporate Literature Circles (Daniels, 2002) and Reciprocal Teaching (Oczkus, 2003) into classroom instruction to increase the dialogue about the reading selections and make reading a more social activity. Males have stressed that working with others provides increased intrinsic motivation (Smith \& Wilhelm, 2002). Guthrie and Wigfield's conception of the engagement model (as cited in NRC, 2006) calls for instruction that offers social interaction with peers and fosters student motivation, strategy use, and growth in conceptual knowledge. This type of instruction leads to higher levels of engagement, which ultimately impacts student achievement.

Teachers should consider providing high-interest reading material for all students, including males, based upon findings from interest surveys. Asher and Markell, along with Anderson, Shirey, Wilson, and Fielding (as cited in Oakhill and Petrides, 2007) found that there was increased comprehension and recall ability from texts that the children expressed a particular interest in reading, and that effect was more pronounced for male students. Interest is often based upon choice. Therefore, teachers might consider allowing choice when selecting reading 
materials and engaging in literacy activities, realizing that choice is a powerful motivator for adolescents, particularly for males. Again, high interest levels of students lead to higher levels of engagement, thus leading to increased achievement.

To further motivate males, teachers might design inquiry projects that structure units around critical questions so that students' reading and writing are genuine inquiry. According to McCray, Vaughn, and LaVonne (2001), “We have to be willing to acknowledge that engagement and motivation play an important role in learning and be mindful of the fact that these students need to perceive themselves as doing complex, sophisticated work, and work that really challenges them” (p. 28). Students tend to perform at higher levels when engaged in authentic assignments based upon real-world situations or problems.

Finally, teachers should focus on pre-reading strategies in an effort to activate students’ prior knowledge or create it, if it is lacking. This can be accomplished through vocabulary instruction, anticipation guides, concept maps, video clips, virtual field trips, photographs, and the like. Simply having prior knowledge may not be sufficient for students to facilitate comprehension. Consequently, educators must build bridges between students’ existing background knowledge and the task at hand. In essence, it is important to make use of what teachers already know about best practices and research-based instruction, including the importance of activating students’ prior knowledge.

\section{Limitations}

The preceding results and conclusions are tempered by certain limitations, therefore reducing the ability to generalize the findings. Homogeneity of participants, the closed hypertext reading, lack of interviews, and the honesty of the participants must all be considered. 
Although the sample size was adequate overall, the number of special education participants was quite small, making it difficult to generalize those specific findings to the population at large. Furthermore, all of the participants in this study attended the same rural school. Ideally, the sample would have included participants from multiple schools with a more diverse student population and varied demographic data. It would also be interesting to conduct a study that focuses on elementary-aged children to compare findings.

The second limitation is the closed hypertext environment that was created for this study. Students were not reading on the Internet, where there is a vast amount of information to explore and interpret. Instead, the electronic narrative contained in the Power Point was identical to that found in the seventh grade textbook. The only exception was that participants had to click on links to get additional information needed to answer several of the questions on the assessment. A study where students are engaged in authentic Internet reading that begins with a question and takes place within an unlimited information space would provide greater insight into the true differences in electronic and print-based comprehension.

This study might also have benefitted from conducting interviews as opposed to administering the student survey, as more information could be gleaned from probing participants' responses. The format of the Conversational Interview contained in the Adolescent Motivation to Read Profile (Pitcher et al., 2007) could serve as a model. By interviewing the participants, as opposed to getting limited information from the survey, student preferences and reading behaviors could better be understood. In addition to the questions posed on the student survey, an additional question should focus on participants' interest in the topic of World War II.

Finally, these findings are based on the assumption that the participants reported accurately and honestly on the student survey. It is possible, however, that participants were 
trying to please their teachers or this researcher and reported using strategies that they did not indeed utilize.

\section{Further Research}

The topic of reading comprehension generally, and electronic text specifically, requires further investigation, as the Internet and other information and communication technologies focus heavily on acquiring knowledge from electronic text. While there is a significant research base in regard to the reading of traditional text, there is still limited research on the nature of reading comprehension on the Internet and other ICT's (Castek et al.). The nature of reading comprehension is constantly evolving, yet there is limited research to direct instruction or yield insights pertinent to comprehension of electronic text. The National Reading Panel has expressed concern that few studies have explored computer technology and literacy instruction.

Additionally, the International Reading Association (2002) has called for "an intensive program of research on literacy and technology issues that will enable us to better understand the rapid changes taking place in the nature of literacy and literacy instruction” (p. 2). Despite these concerns and recommendations, this line of inquiry is still in the infancy stage and requires further research.

A future study assessing Internet-based comprehension, which begins with a question or problem and takes place in unlimited information space, is recommended. While the present study was certainly relevant and yielded pertinent insight into comprehension of electronic text, as well as strategies utilized when reading the said text, it was limited in that it included exclusively closed hypertext. A potential study could build on the present study with the inclusion of Internet reading, thus making the reading more authentic. Additionally, there is little research that focuses on the role of the teacher. Teachers make the most significant contribution 
to learning, and if teachers lack pedagogical training with electronic media or are not well versed in dealing with this medium of text, comprehension could be impacted. As Leu states, "People, not technology, will limit the speed with which new literacies appear” (p. 17). A future study that focuses on the interaction between the teacher and the comprehension of various formats of text would be recommended.

Unfortunately, policy makers, researchers, and educators have somewhat ignored the rapid changes in the field of literacy that have been prompted by the Internet and other ICTs (Coiro, 2007). Until our field realizes that online and offline reading are not synonymous and eludes the assumption that online reading skills are technology skills instead of reading comprehension skills, we will stay grounded in the past instead of the future. Possibly, findings from this study will open new doors for research and practice to address the needs of adolescent readers of this $21^{\text {st }}$ century. As Leu (2007) recommends, we must begin to advance our understanding of how best to continue on a journey that effectively prepares students for their literacy futures in this age of information and technology. 


\section{References}

Alvarez, O. (2006). Developing digital literacies: Educational initiatives and research in colombia. In M. McKenna, L. Labbo, R. Kieffer \& D. Reinking (Eds.), International Handbook of Literacy and Technology (pp. 29-40). USA: Lawrence Erlbaum Associates.

Alvermann, D. (2001). Effective Literacy Instruction for Adolescents. Executive Summary and Paper Commissioned by the National Reading Conference. Chicago, IL: National Reading Conference.

Baker, S., Simmons, D., \& Kame'euni, E. Vocabulary acquisition: Synthesis of the research. Retrieved December 18, 2008, from www.voyagerlearning.com/research.

Bartlett, C.(n.d.). Reading comprehension on the Web. Retrieved on July 17, 2008, from www.learnnc.org/lp/pages/657style.

Biancarose, C., \& Snow, C. E. (2006). Reading next-A vision for action and research in middle and high school literacy: A report to the Carnegie Corporation of New York ( ${ }^{\text {nd }}$ ed.). Washington, DC: Alliance for Excellent Education.

Brozo, W. (2002). To be a boy, to be a reader: Engaging teen and preteen boys in active literacy. Newark, DE: International Reading Association.

Castek, J., Hartman, D., Leu, D., Coiro, J., Henry, L., \& Zawilinski, L. (n.d.). Thinking about our future as researchers: New literacies, new challenges and new opportunities.

Cohen, V. (2006). Strategies for comprehending electronic text in digitally mediated times. Retrieved on July 6, 2008, from http://www.formatex.org/micte2006/pdf/170-174.pdf. 
Coiro, J. (2003). Reading comprehension on the internet: Expanding our understanding of reading comprehension to encompass new literacies. Retrieved July 18, 2008, from www.readingonline.org/electronic/elec_index.asp?HREF=/electronic/RT/2-03_ column/index.html.

Coiro, J. (2005). Making sense of online text. [Electronic version]. Educational Leadership, 30-35.

Coiro, J. \& Dobler, E. (2007). Exploring the online reading comprehension strategies used by sixth-grade skilled readers to search for and locate information on the Internet. Reading Research Quarterly, 42, 214-257.

Coiro, J., Knobel, M., Lankshear, C., \& Leu, D. (2008). Central issues in new literacies and new literacies research. In J. Coiro, M. Knobel, C. Lankshear, \& D. Leu (Eds.), Handbook of research on new literacies (pp. 25-32). Mahwah, NJ: Erlbaum

Compton-Lily, C. (2008). What can new literacy studies offer to the teaching of struggling readers? The Reading Teacher, 63, 88-91.

Daniels, H. (2002). Literature circles: Voice and choice in book clubs and reading groups. Portland, Maine: Stenhouse Publishers.

Duke, N., Schmar-Dobler, E. \& Zhang, S. (2006). Comprehension and technology. In M. McKenna, L. Labbo, R. Kiffer, \& D. Reinking (Eds.), International Handbook of Literacy and Technology (pp. 317-326). USA: Lawrence Erlbaum Associates.

Fry, S. (2007). Supporting middle school social studies students' reading comprehension with an electronic pop-up dictionary. In C. Crawford et al. (Eds.), Proceedings of Society for Information Technology and Teacher Education International Conference 2007 (pp. 3539-3541). Chesapeake, VA: AACE. 
Gill, S. (2008). The comprehension matrix: A tool for designing comprehension instruction. The Reading Teacher, 62, 106-113.

Grimshaw, S., Dungworth, N.M., McKnight, C., and Morris, A. (2007). Electronic books: Children’s reading comprehension. [Electronic version]. British Journal of Educational Technology, 384, 583-599.

Handsfield, J., Dean,T., and Cielocha, K. (2008). Becoming critical consumers and producers of text: Teaching literacy with Web 1.0 and Web 2.0. The Reading Teacher, 63, 40-49.

Hobbs, R. Multiple visions of multimedia literacy: Emerging areas of synthesis. In M. McKenna, L. Labbo, R. Kiffer \& D. Reinking (Eds.), International Handbook of Literacy and Technology (pp. 29-40). USA: Lawrence Erlbaum Associates.

International Reading Association. (2002). Integrating Literacy and Technology in the Curriculum (Position Statement). Newark, DE: Author.

International Reading Association and National Council of English Teachers. (1996). Standards For English and language arts. Newark, DE: International Reading Association; Urbana, IL: National Council of Teachers of English.

Joly, M., Capovilla, A., Bighetti, C., \& Nicolau, A. (2005). Reading comprehension of freshman students: Comparing printed and digital texts. Retrieved February 20, 2008, from http:// www.formatex.org/micte2005/12.

Karchmer, R. The journey ahead: Thirteen teachers report how the internet influences literacy and literacy instruction in the K-12 classrooms. Retrieved on June 5, 2008 from www. accessmylibrary.com/comsite5/bin/aml-landing.

Kleiman, G. \& Peterson, K. (2004). Technology and teaching children to read. Retrieved July 18, 2008 from www.neirtec.org/reading_report/. 
Kujawa, S., \& Huske, L. (1995). The strategic teaching and reading project guidebook. Oak Brook, IL: North Central Regional Educational Laboratory.

Lemke, J. Toward Critical multimedia literacy: Technology, research, and politics. In M. McKenna, L. Labbo, R. Kiffer \& D. Reinking (Eds.), International Handbook of Literacy and Technology (pp. 29-40). USA: Lawrence Erlbaum Associates.

Lenhart, A., Madden, M., \&Hitlin, P. (205). Teens and technology. Washington, DC: Pew Internet \& American Life Project. Retrieved July 17, 2008, from http://www.pew Internet.org/pdfs/PIP_Teens_Tech_July2005web.pdf.

Leu, D.(2001). Internet project: Preparing students for new literacies in a global village. The Reading Teacher, 54, 6.

Leu, D., Kinzer, C., Coiro, J. \& Cammack, D. (2004). Towards a theory of new literacies Emerging from the internet and other information and communication technologies. Retrieved on March 3, 2009 from www.readingonline.org/newliteracies/leu.

Matthew, K. (2007). A comparison of the influence of interactive CD-ROM storybooks and traditional print storybooks on reading comprehension. Journal of Research Computing in Education, 29, 263-275.

McCray, A., Vaughn, D., \& LaVonne, I. (2001). Not all students learn to read by third grade: middle school students speak out about their reading disabilities. Journal of Speci Education, 35, 17-30.

McKenna, M, Reinking, D., Labbo, L., \& Kieffer, R. (1999). The electronic transformation of literacy and its implications for the struggling reader. Reading \& Writing Quarterly, 15, 111-126. 
McKeown, Beck, Sinatra, \& Loxterman. (1992). The contribution of prior knowledge and coherent text to comprehension. Reading Research Quarterly, 27, 79-93.

Mokhtari, K., Kymes, A., \& Edwards, P. (2008). Assessing new literacies of online reading comprehension: An informative interview with w. ian o’byrne, lisa zawilinski, j. greg mcverry, and donald j. leu at the university of connecticut. The Reading Teacher, 62, 2008.

Morgan, S; Reichert, T, \& Harrison, T. (2002). From numbers to words. Boston, MA: Allyn \& Bacon.

National Reading Panel. (2000). Teaching children to read: An evidenced-based assessment of the scientific research literature on reading and its implications for reading instructionReport of the subgroups. Washington, D.C.: National Institute of Child Health and Human Development, National Institutes of Health, U.S. Department of Health and Human Services.

Oakhill, J. \& Petrides, A. (2007). Sex differences in the effects of interest on boys' and girls' reading comprehension. British Journal of Psychology, 98, 223-235.

Oczkus, L. (2003). Reciprocal teaching at work: Strategies for improving reading comprehension. Newark, Delaware: International Reading Association.

Pearman, C. (2008). Independent Reading of CD-Rom storybooks: Measuring comprehension with oral retellings. The Reading Teacher, 61, 594-602.

Pitcher, S., Albright, L., DeLaney, C., Walker, N., Seunarineingh, K., Mogge, s., Headley, K., Ridgeway, V., Peck, S., Hunt, R., \& Dunston, P. (2007). Assessing adolescents’ motivation to read. Journal of Adolescent and Adult Literacy, 10, 378-396. 
Pressley, M. (2006). Reading instruction that works: The case for balanced literacy ( $3^{\text {rd }}$ ed.) New York: Guilford Press.

Rand Reading Study Group. (2002). Reading for understanding: Toward an R\&D program in reading comprehension. Santa Monica, CA: RAND. Retrieved July 17, 2008, from www.rand.org/pubs/monograph_reports/MR1465/MR1465.pdf.

Reinking, D. (1993). Electronic literacy. Retrieved July 31, 2008, from www.teach.virginia. edu/go/clic/nrrc/reinking.html.

Slocumb, P. (2004). Hear our cry: Boys in crisis. Highlands, Texas: Aha Process, Inc.

Smith, M. \& Wilhelm, J. (2002). Reading don't fix no chevys: Literacy in the lives of young men. Portsmouth, NH: Heinemann.

Smith, N. (1965). American reading instruction. Newark, DE: International Reading Association.

Sutherland-Smith, W. (2002). Weaving the literacy Web: Changes in reading from page to screen. The Reading Teacher, 55, 662-668.

Thompson, L. (Ed), Voyager connection. (pp. 15-17). Dallas, Tx: Voyager Expanded Learning.

Walsh, M., Asha, J., \& Sprainger, N. (2007). Reading digital texts. Journal of Language and Literacy, 30, 40-53.

Waniek, J., Brunstein, A., Naumann, A., \& Krems, J. (2003). Interaction between text structure representation and situation model in hypertext reading. Swiss Journal of Psychology, 62, $103-111$.

Williams, B. (2007). Girl power in a digital world: Considering the complexity of gender, literacy, and technology. Journal of Adolescent \& Adult Literacy, 50, 300-307. 
Zumbach, J. \& Maryam,M. (2008). Cognitive lad in hypermedia reading comprehension: Influence of text type and linearity. Computers in Human Behavior, 24, 875-887. 
Appendix A

Student ID \#

\section{Prior Knowledge Questions- World War II}

1. Who fought in World War II?

2. Who were the Nazis?

3. What was the Holocaust?

4. What happened at Pearl Harbor?

5. Who were the Allies and Axis Powers? 
Appendix B

Student ID \#

Type of text

\section{Retell Assessment- World War II}

On the lines provided below, please retell what you remember about World War II from what you just read. Begin with a main idea statement and then elaborate with supporting details. Please write in paragraph form. 
Appendix C

\section{Retelling Scoring Sheet}

Main Idea

As troubles grew

dictators came to power.

\section{Details}

In Japan

the military took over the government

In the Soviet Union

Stalin took over

after Lenin died.

Brutal dictators arose

in Italy

and Germany.

They attracted followers

by preaching fascism.

Mussolini made Italy

the first fascist state.

Hitler led the first fascist movement.

Hitler took over

the German government

in 1933.

Main Idea

The Axis Powers

declared war 
on Germany.

\section{Details}

Hitler aimed to take revenge on Germany

by expanding German territory.

He attacked Poland

in 1939.

The Allies,

Great Britain and France,

declared war on Germany.

The Axis Powers formed.

Germany, Italy, and Japan

joined forces.

\section{Main Idea}

WWII was a new kind of war.

\section{Details}

Tanks and trucks

allowed armies to move quickly.

Bombers flew long distances.

With new tactics,

Germany quickly defeated Poland

in a Blitzkreig, or "lightning war".

\section{Main Idea}

The United States

joined the Allies 
and they won the war.

\section{Details}

_On December 7, 1941,

Japan attacked

Pearl Harbor.

The United States

led by President Franklin Roosevelt

joined the Allies.

For the next 2.5 years

battles raged in Europe,

Europe,

North Africa,

the Middle East,

Asia,

and the South Pacific.

In June of 1944,

British troops landed in France

and pushed into Germany.

Germany surrendered

in May of 1945.

The United States

dropped atomic bombs

on Hiroshima

and Nagasaki.

Japan surrendered. 
The war was over.

\section{Main Idea}

There were many effects of the war.

The world was vastly changed.

\section{Details}

It was the deadliest conflict inhuman history.

34 million soldiers were injured.

22 million died.

30 million civilians lost their lives.

Many were victims

of the Holocaust.

the Nazi’s efforts

to wipe out the Jewish people.

Jews were sent to special camps

called concentration camps.

Six million Jews died

in this genocide, the deliberate destruction of a people.

Thousands of Japanese died because of the atomic bombs.

The war weakened economies. and governments.

The Unites States

and Russia

became the world's strongest powers. 
They began to distrust cone another.

The distrust led to the Cold War,

rivalry between the superpowers

with no direct fighting.

The Soviets set up Communist states

in Eastern Europe.

Germany divided in two.

West Germany

became a democracy.

East Germany

became a Communist nation.

\section{Main Idea}

There were several notable leaders of the war.

Winston Churchill

Franklin Roosevelt

Joseph Stalin

Adolf Hitler

Benito Mussolini

Hideki Tojo

Main Idea

Anne Frank

was a teenager living in Germany

when Hitler came to power.

\section{Details}

Anne and her family 
fled to Amsterdam.

Nazis were rounding up Jews there.

Her family hid

in a friend's home.

She writes in a diary

and describes people being taken away in droves.

They are treated roughly

and transported in cattle cars

to Westerbork.

She assumes they are being killed.

She has not lost her ideals,

even though they might seem impractical

and absurd.

She believes that everyone is still good at heart.

\section{Main Idea}

The Nazis sent Jews away

to concentration camps.

\section{Details}

Concentration camps

are special camps

where Jews and others

were worked to death

or murdered 
Appendix D

Student ID \#

Type of text

\section{Constructed-response Assessment- World War II}

Please answer the questions to the best of your ability. Write your responses on the lined paper that has been provided.

1. Cause-effect: Identify an event that led to World War II and a result, or effect, of the war.

2. On what side of the war did the United States join?

3. Who was the president of the United States during this war?

4. Name a leader of the Allies.

5. Name a leader of the Axis Powers.

6. What do you think Anne Frank meant when she said, "It's a wonder that I haven't abandoned all my ideals; they seem so absurd and impractical?”

7. What were concentration camps?

8. Do you feel that the atomic bomb was justified as a means to end the war against Japan? Support your opinions with facts that you read in the text. 
Appendix E

\section{Brief Constructed Response Rubric Western County School System}

3 points: The response demonstrates an understanding of the complexities of the text.

$\checkmark$ Addresses the demands of the question

$\checkmark$ Effectively uses text-based and/or text relevant information to clarify and extend understanding.

2 points: The response demonstrates a general understanding of the text.

$\checkmark$ Partially addresses the demands of the question

$\checkmark$ Uses text-based and/or text-relevant information to show understanding

1 point: The response demonstrates minimal understanding of the text.

$\checkmark$ Minimally addresses the demands of the question

$\checkmark$ Uses minimal information to show some understanding of the text in relation to the question

0 points: The response is completely incorrect, irrelevant to the question, or missing.

Text-based: coming directly from the text

Text-relevant: having a bearing on or connection to the text. 
Appendix F

Student ID \#

Type of Text

\section{Student Survey}

Read each sentence below and then please circle if you agree or disagree with the statement.

1. I like the type of text that I was assigned to read (electronic or print text). Agree Disagree No preference

2. I would have preferred reading the other type of text. Agree Disagree No preference

3. Most of my reading done outside of school is electronic text. Agree Disagree Name something that you recently read in electronic format.

4. If our school was voting to keep our current textbooks or purchase electronic textbooks, I would choose the electronic textbooks. Agree Disagree No preference

5. I spend 3 hours or more reading electronic text each week. Agree Disagree

6. Most of my electronic text reading is browsing or sampling text, as opposed to reading text. Agree Disagree

7. I believe that I comprehend electronic text better. Agree Disagree No Preference

Place a check in front of the statements that describe the reading strategies that you used during this study.

I made predictions while I was reading.

I self-monitored my comprehension while reading.

I connected what I was reading with my prior knowledge.

I used the WIN strategy to identify main ideas.

I summarized at the end of each section of text.

I used the CPR strategy to figure out the meaning of unknown words.

I used the text features such as subtitles, bolded words, photos, and charts.

I carefully read the summary at the end of the lesson. 
Please list any other strategies that you used.

If you read the electronic text, please answer the following by circling the statement that best describes your reading behaviors.

How many links did you click on while reading this text? All Most A few None

Which link was most helpful? Definitions Photos Chart Diary Entry

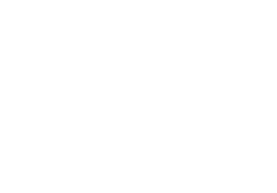

